\title{
Elevated TRPV4 Levels Contribute to Endothelial Damage and Scarring in Experimental Spinal Cord Injury
}

\author{
DHemant Kumar, ${ }^{1}$ Chang Su Lim, ${ }^{2}$ Hyemin Choi, ${ }^{1}$ Hari Prasad Joshi, ${ }^{1}$ Kyoung-Tae Kim, ${ }^{3,4}$ Yong Ho Kim, ${ }^{5}$ \\ Chul-Kyu Park, ${ }^{5}$ Hwan Myung Kim, ${ }^{2}$ and In-Bo Han ${ }^{1}$ \\ ${ }^{1}$ Department of Neurosurgery, CHA University School of Medicine, CHA Bundang Medical Center, Seongnam-si, Gyeonggi-do, Republic of Korea, 13488, \\ ${ }^{2}$ Department of Energy System Research and Department of Chemistry, Ajou University, Suwon, Gyeonggi-do, Republic of Korea, 16499, ${ }^{3}$ Department of \\ Neurosurgery, School of Medicine, Kyungpook National University, Daegu, Republic of Korea, 41944, ${ }^{4}$ Department of Neurosurgery, Kyungpook National \\ University Hospital, Daegu, Republic of Korea, 41944, and ${ }^{5}$ Gachon Pain Center and Department of Physiology, College of Medicine, Gachon University, \\ Incheon, Republic of Korea, 13120
}

Currently, the role of transient receptor potential vanilloid type 4 (TRPV4), a nonselective cation channel in the pathology of spinal cord injury (SCI), is not recognized. Herein, we report the expression and contribution of TRPV4 in the pathology of scarring and endothelial and secondary damage after SCI. TRPV4 expression increased during the inflammatory phase in female rats after SCI and was expressed primarily by cells at endothelial-microglial junctions. Two-photon microscopy of intracellular-free $\mathrm{Ca}^{2+}$ levels revealed a biphasic increase at similar time points after SCI. Expression of TRPV4 at the injury epicenter, but not intracellular-free Ca ${ }^{2+}$, progressively increases with the severity of the injury. Activation of TRPV4 with specific agonist altered the organization of endothelial cells, affected tight junctions in the hCMEC/D3 BBB cell line in vitro, and increases the scarring in rat spinal cord as well as induced endothelial damage. By contrast, suppression of TRPV4 with a specific antagonist or in female Trpv4 KO mouse attenuated inflammatory cytokines and chemokines, prevented the degradation of tight junction proteins, and preserve blood-spinal cord barrier integrity, thereby attenuate the scarring after SCI. Likewise, secondary damage was reduced, and behavioral outcomes were improved in Trpv4 K0 mice after SCI. These results suggest that increased TRPV4 expression disrupts endothelial cell organization during the early inflammatory phase of SCI, resulting in tissue damage, vascular destabilization, blood-spinal cord barrier breakdown, and scarring. Thus, TRPV4 inhibition/knockdown represents a promising therapeutic strategy to stabilize/protect endothelial cells, attenuate nociception and secondary damage, and reduce scarring after SCI.

Key words: blood-spinal cord barrier; endothelial cell; scarring; spinal cord injury; TRPV4; two-photon microscopy

Significance Statement

TRPV4, a calcium-permeable nonselective cation channel, is widely expressed in both excitable and nonexcitable cells. Spinal cord injury (SCI) majorly caused by trauma/accidents is associated with changes in osmolarity, mechanical injury, and shear stress. After SCI, TRPV4 was increased and were found to be linked with the severity of injury at the epicenter at the time points that were reported to be critical for repair/treatment. Activation of TRPV4 was damaging to endothelial cells that form the blood-spinal cord barrier and thus contributes to scarring (glial and fibrotic). Importantly, inhibition/knockdown of TRPV4 prevented these effects. Thus, the manipulation of TRPV4 signaling might lead to new therapeutic strategies or combinatorial therapies to protect endothelial cells and enhance repair after SCI.

\section{Introduction}

The pathology of spinal cord injury (SCI) is multifaceted, encompassing the initial tissue disruption from the primary trauma and secondary injury progression, involving inflammation, the death of endothelial cells (ECs), neurons, and glia, extracellular matrix remodeling, scarring, and cavitation (Liu et al., 1997; Ling and 
Liu, 2007). Vascular pathology can be observed minutes after SCI, initiated by the death of ECs, which, along with pericytes, astrocytes, and neurons, comprise the microvasculature under normal conditions (Whetstone et al., 2003; Casella et al., 2006). The death of ECs continues throughout the acute phase of injury (Benton et al., 2008), predominantly at the injury epicenter, causing substantial hemorrhage and disturbance of vascular autoregulation that subsequently contributes to the death of neurons and glial cells (Casella et al., 2002, 2006). Microvessels in the spinal cord support the neural parenchyma not only by supplying blood and oxygen but also by continuously secreting neurotrophins, such as BDNF and angiopoietins, which support regenerating spinal cord tissue (Guo et al., 2008). SCI therapies targeting EC preservation have shown remarkable potential (Fassbender et al., 2011; Kumar et al., 2018c); however, therapeutic endothelial protection/stabilization within penumbral microvasculature remains largely unexplored because of a lack of understanding of the key molecular pathways triggered after SCI.

Most mammalian tissues, including the peripheral nervous system and the CNS (Montell et al., 2002; Ramsey et al., 2006), express transient receptor potential vanilloid type 4 (TRPV4), a calcium-permeable nonselective cation channel (Liedtke et al., 2000; Strotmann et al., 2000) that is currently recognized as a polymodal ionotropic receptor (Kumar et al., 2018a). TRPV4 channels are activated by a wide range of stimuli (Liedtke et al., 2000; Strotmann et al., 2000; Willette et al., 2008; Kumar et al., 2018a), as well as intracellular signaling pathways (AlessandriHaber et al., 2004, 2006; Grant et al., 2007; Zhao et al., 2014). The abundant presence of ion channels in the plasma membrane of ECs suggests their functional role (Nilius and Droogmans, 2001). Ion channels in ECs control several functions, including intracellular $\mathrm{Ca}^{2+}$ signals, production and release of many vasoactive factors, regulates macromolecules and also involved in controlling intercellular permeability, EC proliferation, and angiogenesis (Nilius and Droogmans, 2001). Reports suggest that increase in TRPV4 activity disintegrated the cell junctions of blood-CSF barrier (Narita et al., 2015). However, TRPV4 expression and its role following SCI have not been characterized.

Here, we show that TRPV4 expression is associated with the severity of injury at the epicenter after SCI. We demonstrate that TRPV4 upregulation and activation disrupt EC organization after SCI and that ECs are better preserved in the absence of TRPV4. Furthermore, the deletion of TRPV4 signaling significantly impacts SCI-induced inflammatory cascades, blood-spinal cord barrier (BSCB) integrity, degree of scarring, and spontaneous locomotor recovery after SCI. Notably, inhibition or deficiency of TRPV4 was beneficial for endothelial factors, such as BDNF, neurotrophins, and angiopoietin, in the CNS after SCI.

\section{Materials and Methods}

Subjects and surgical procedures

A total of 211 female Sprague Dawley rats (220-240 g), for this study, were purchased from Orient Bio. Mice heterozygous (B6.129X1Trpv4<tm1Msz $>$ ) for Trpv4 deficiency (Suzuki et al., 2003) were purchased from RIKEN BioResource Centre and intercrossed to generate Trpv4 KO mice. The genotype was examined using PCR with primer sequence as given in Table 1 . WT $(\mathrm{C} 57 \mathrm{BL} / 6 \mathrm{JJcl})$ were purchased from Orient Bio served as controls. Thirty-eight female WT and 22 female KO mouse were used in the study. Animals were housed in a facility with $55 \%-65 \%$ humidity at $24 \pm 2^{\circ} \mathrm{C}$ with a $12 \mathrm{~h} \mathrm{light/dark} \mathrm{cycle} \mathrm{and} \mathrm{free}$ access to food and water. All animal experiments were performed as per the approved guidelines by the Institutional Animal Care and Use Committee of CHA University (IACUC160073) and Principles of laboratory
Table 1. Primer sequences for the genes of interest used in the current study

\begin{tabular}{|c|c|c|}
\hline Oligo name & $\begin{array}{l}\text { Reverse/ } \\
\text { forward }\end{array}$ & Sequence $\left(5^{\prime} \rightarrow 3^{\prime}\right)$ \\
\hline \multirow[t]{2}{*}{ TRPV4 (rat) } & Forward & CCACCCCAGTGACAACAAG \\
\hline & Reverse & GGAGCTTTGGGGCTCTGT \\
\hline \multirow[t]{2}{*}{ Occludin (rat) } & Forward & ATCTAGAGCCTGGAGCAACG \\
\hline & Reverse & GTCAAGGCTCCCAAGACAAG \\
\hline \multirow[t]{2}{*}{ PACSIN3 } & Forward & AAGGCCCCTGAGAGAGGAC \\
\hline & Reverse & СTCCCAGAAACTGCCCACTA \\
\hline \multirow[t]{2}{*}{ IL-6 (rat) } & Forward & TGATGGATGCTTCCAAACTG \\
\hline & Reverse & GAGCATTGGAAGTTGGGGTA \\
\hline \multirow[t]{2}{*}{ TNF- $\alpha$ (rat) } & Forward & ACTGAACTTCGGGGTGATTG \\
\hline & Reverse & GCTTGGTGGTTTGCTACGAC \\
\hline \multirow[t]{2}{*}{ H0-1 (rat) } & Forward & GTCAAGCACAGGTGACAGA \\
\hline & Reverse & CTGCAGCTCCTCAAACAGC \\
\hline \multirow[t]{2}{*}{ Neuropilin-1 (rat) } & Forward & CATAGTGGGCTCGGACTGA \\
\hline & Reverse & GGGTCCAGCTGTAGGCACT \\
\hline \multirow[t]{2}{*}{ ANG-1 (rat) } & Forward & TTTAGATTGGAAGGGCCACA \\
\hline & Reverse & ATGCGCCCTTATGCTAACAG \\
\hline \multirow[t]{2}{*}{ ANG-2 (rat) } & Forward & СCCACTTCTGAGCTTCACATC \\
\hline & Reverse & CATAGGAGGAAACCTGTTCACC \\
\hline \multirow[t]{2}{*}{ Nucleophosmin (rat) } & Forward & CCGGATGACTGACCAGGA \\
\hline & Reverse & GCAACTATTACAGAAATGAAGACAGAA \\
\hline \multirow[t]{2}{*}{ Arachidonate 15 lipooxygenase (rat) } & Forward & GAAGCTGCTACGACCCTGTC \\
\hline & Reverse & CCAAGGTATCCTGACACATCC \\
\hline \multirow[t]{2}{*}{ Aquaporin-9 (rat) } & Forward & CCTTCTGAGAAGGACCGAGCC \\
\hline & Reverse & СTTGAACCACTCСATCСTTCC \\
\hline \multirow[t]{2}{*}{ KCNJ10 (rat) } & Forward & GGAGGAGATCCTCTGGGGTT \\
\hline & Reverse & CCACTGGGAGATGCCACTTT \\
\hline \multirow[t]{2}{*}{ iNOS (rat) } & Forward & CTTTGCCACGGACGAGAC \\
\hline & Reverse & TCATTGTACTCTGAGGGCTGAC \\
\hline \multirow[t]{2}{*}{ GAPDH (rat) } & Forward & САACTCCCTCAAGATTGTCAGCAA \\
\hline & Reverse & GGCATGGACTGTGGTCATGA \\
\hline \multirow[t]{2}{*}{ Occludin (mouse) } & Forward & ССTCCAATGGCAAAGTGAAT \\
\hline & Reverse & СTCCCCACCTGTCGTGTAGT \\
\hline \multirow[t]{2}{*}{ VEGF (mouse) } & Forward & CGCAAGAAATCCCGGTTTAA \\
\hline & Reverse & САAATGCTTTCTCCGCTC TGA \\
\hline \multirow[t]{2}{*}{$\|-1 \beta$ (mouse) } & Forward & TTGTGGCTGTGGAGAAGCTGT \\
\hline & Reverse & AACGTCACACACCAGCAGGTT \\
\hline \multirow{2}{*}{ IL-6 (mouse) } & Forward & GCTACCAAACTGGATATAATCAGGA \\
\hline & Reverse & CCAGGTAGCTATGGTACTCCAGAA \\
\hline \multirow[t]{2}{*}{ TNF- $\alpha$ (mouse) } & Forward & AGCAAACCACCAAGTGGAGGA \\
\hline & Reverse & GCTGGCACCACTAGTTGGTTGT \\
\hline \multirow[t]{2}{*}{ Mac-1 (mouse) } & Forward & СCTTGTTCTCTTTGATGCAG \\
\hline & Reverse & GTGATGACAACTAGGATCTT \\
\hline \multirow[t]{2}{*}{ CCL-2 (mouse) } & Forward & GAAGGAATGGGTCCAGACAT \\
\hline & Reverse & ACGGGTCAACTTCACATTCA \\
\hline \multirow[t]{2}{*}{ CCL-3 (mouse) } & Forward & TTTGAAACCAGCAGCCTTTGCTCC \\
\hline & Reverse & TCAGGCATTCAGTTCCAGGTCAGT \\
\hline GAPDH (mouse) & Forward & CCATTTTGTCTACGGGACGA \\
\hline & Reverse & GGGTTCCTATAAATACGGACTGC \\
\hline
\end{tabular}

\begin{tabular}{lll} 
Genotyping & & \\
trpv4 exon 4R & Forward & TGTTCGGGGTGGTTTGGCCAGGATAT \\
trpv4 neo & Forward & GCTGCATACGCTTGATCCGGTAC \\
trpv4 exon 4R & Reverse & GCTGAACCAAGGACACTTGCATAG \\
\hline
\end{tabular}

PACSIN3, Protein kinase C and casein kinase substrate in neurons 3; H0-1, heme oxygenase; KCJN10, ATP-sensitive inward rectifier potassium channel 10; iNOS, inducible nitric oxide; $\mathrm{CL}-2, \mathrm{C}-\mathrm{C}$ motif chemokine ligand-2; CCL-3, C-C motif chemokine ligand-3; Mac-1, macrophage-1 antigen.

animal care (National Research Council, 2011). Animals were anesthetized for laminectomies exposing the $\sim \mathrm{T} 10$ segment of the spinal cord as previously reported (Kumar et al., 2018b). The vertebral column was stabilized and supported by Allis clamps at T8, and T12 spinous processes as previously described (Kumar et al., 2018b,c) (see Fig. 1A). A metal impounder (rats: $20 \mathrm{~g} / 5 \mathrm{~min}$ [mild injury], $35 \mathrm{~g} / 5 \mathrm{~min}$ [moderate injury], or $50 \mathrm{~g} / 5 \mathrm{~min}$ [severe injury]; mice: $20 \mathrm{~g} / 1 \mathrm{~min}$ ) was then gently applied to T10 dura, resulting in weight compression SCI. Animals were anesthetized for laminectomies exposing the $\sim \mathrm{T} 10$ segment of the spinal cord, 
and a transverse cut was made to create a right hemisection injury. The surgical site was closed after SCI, by suturing the muscle and fascia using silk suture followed by suturing the skin. Povidone-iodine was applied externally to the surgical site, and animals were kept on a heating pad to maintain body temperature until they recovered from anesthesia, and then $5 \mathrm{ml}$ (rats) or $0.5 \mathrm{ml}$ (mouse) of $0.9 \%$ sterile saline-injected subcutaneously. Manual bladder expression was performed twice daily (morning and evening) until a bladder reflex was established.

\section{Cell culture, drugs, and treatments}

Blood-brain barrier (BBB) hCMEC/D3 cell line (Millipore) and human umbilical vascular endothelial cells (HUVECs; ATCC) were used to understand the biological role of TRPV4 activation or inhibition in ECs. hCMEC/D3 and HUVECs were cultured in fully supplemented endothelial growth medium (PromoCell, Human Centered Science) as per the manufacturer's instructions. GSK1016790A and RN-1734 were purchased from Sigma Millipore. GSK1016790A and RN-1734 were dissolved in DMSO and then used at the functional concentration of 1 and $10 \mu \mathrm{M}$, respectively, for in vitro studies. RN-1734 was dissolved in 5\% DMSO, $5 \% \mathrm{~N}, \mathrm{~N}$-dimethylacetamide and remaining saline and administered intraperitoneally at the dose of $5 \mathrm{mg} / \mathrm{kg} 1 \mathrm{~h}$ after SCI. Rats were killed at $8 \mathrm{~h}$ after injury (HPI-8; calcium imaging) or $1 \mathrm{~d}$ postinjury (DPI-1; biochemical parameters) after vehicle or RN-1734 treatment. GSK1016790A was first dissolved in DMSO, and then serial dilution was performed to get the final concentration of $50 \mathrm{pmol}[0.3 \%$ DMSO in aCSF (Tocris Bioscience)]; subsequently, $10 \mu \mathrm{l}$ was injected at $\sim$ T10 level of spinal cord with the help of Legato 130 Syringe Pump (KD Scientific).

\section{Behavioral assessment}

Hindlimb locomotor score. Hindlimb locomotor function was evaluated using the open-field Basso Mouse Scale (BMS) locomotor test (Basso et al., 2006) on $1,3,7,14,21$, and $28 \mathrm{~d}$ following injury in WT $(n=10)$ and TRPV4 KO $(n=10)$ mice. The scoring ranged from 0 points (no ankle movement) to 9 points (complete functional recovery). The animal's hindlimb motor functions were evaluated by two experienced investigators who were blinded to treatment group.

Test for nociception. Nociception in mice was assessed using the hotplate method at pre-SCI (basal), 1, 3, 7, 14, 21, and $28 \mathrm{~d}$ after SCI. Briefly, mice ( $n=6 /$ group) were placed on the surface of the hotplate $(25.4 \times$ $25.4 \mathrm{~cm}$; Ugo Basile) heated to $54^{\circ} \mathrm{C}$, which was surrounded by a transparent Plexiglas chamber (see Fig. 6A). The latency to respond was measured with either a hindpaw lick or flick, with a cutoff threshold of $20 \mathrm{~s}$ to prevent tissue injury. Mice were removed immediately from the hotplate after a response. A total of three readings were used to determine the average reaction time.

$q R T-P C R$

qRT-PCR was performed at respective time points using a SYBR Green Master Mix, and the mRNA detection was analyzed using an ABI StepOne Real-time PCR System (Applied Biosystems) (Kumar et al., 2018c). Primer sequences for the genes of interest used in the current study were as given in Table 1: Typical profile times were the initial step, $95^{\circ} \mathrm{C}$ for $10 \mathrm{~min}$ followed by a second step at $95^{\circ} \mathrm{C}$ for $15 \mathrm{~s}$, and $60^{\circ} \mathrm{C}$ for $30 \mathrm{~s}$ for 40 cycles with a melting curve analysis. The target mRNA level was normalized with the level of the GAPDH and compared with the control. Data were analyzed using the $\Delta \Delta \mathrm{CT}$ method.

\section{Western blot analysis}

hCMEC/D3 cells were collected after $24 \mathrm{~h}$ of drug treatment. Spinal cord tissues were collected at DPI- 1 and DPI- 28 and washed with PBS, placed at $4^{\circ} \mathrm{C}$, and homogenized in lysis buffer (PRO-PREP, iNtRON Biotechnology) and centrifuged at $14,000 \mathrm{rpm}$ at $4^{\circ} \mathrm{C}$ for $15 \mathrm{~min}$. The supernatant was collected for determination of protein concentration using Bio-Rad DC Protein Assay. Protein concentration was determined by VersaMax microplate reader. Equal amounts of protein $(40 \mu \mathrm{g})$ were separated electrophoretically by $10 \%$ SDS-PAGE electrophoresis, and the resolved proteins were transferred to PVDF membranes (\#162-0177, Bio-Rad). The membranes were then incubated for $1 \mathrm{~h}$ with $5 \%$ nonfat skim milk prepared in TBS buffer to block nonspecific binding. The membranes were then incubated overnight in cold room with primary
Table 2. Primary antibody information used for immunoblot analysis

\begin{tabular}{llll}
\hline $\begin{array}{l}\text { Primary } \\
\text { antibody }\end{array}$ & Dilution & Producer company & Code number \\
\hline TRPV4 & $1: 200$ & Alomone Labs, Israel & ACC-034 \\
ANG-1 & $1: 10,000$ & Abcam, UK & ab183701 \\
NF & $1: 10,000$ & Abcam, UK & ab8135 \\
Z0-1 & $1: 1000$ & Cell Signaling Technology, USA & 8193 \\
Z0-2 & $1: 1000$ & Cell Signaling Technology, USA & 2847 \\
Claudin-1 & $1: 1000$ & Cell Signaling Technology, USA & 13255 \\
CD2AP & $1: 1000$ & Cell Signaling Technology, USA & 2135 \\
Afadin & $1: 1000$ & Cell Signaling Technology, USA & 13531 \\
IL-6 & $1: 1000$ & Abcam, UK & ab6672 \\
Occludin & $1: 500$ & Invitrogen, USA & $33-1500$ \\
CD-31 & $1: 500$ & Abcam, UK & ab28364 \\
AKT & $1: 1000$ & Cell Signaling Technology, USA & 9271 \\
JNK & $1: 1000$ & Cell Signaling Technology, USA & 4668 \\
ERK & $1: 1000$ & Cell Signaling Technology, USA & 4377 \\
Caspase-3 & $1: 1000$ & Cell Signaling Technology, USA & 96625 \\
Iba-1 & $1: 1000$ & FUJIFILM Wako, Japan & $019-19741$ \\
Connexin-43 & $1: 5000$ & Abcam, UK & ab11369 \\
GFAP & $1: 10,000$ & Abcam, UK & Ab16997 \\
Actin & $1: 10,000$ & ABM, Canada & G043 \\
\hline
\end{tabular}

Table 3. Primary antibody information used for immunohistochemistry analysis

\begin{tabular}{llll}
\hline Primary antibody & Dilution & Producer company & Code number \\
\hline Anti-TRPV4 & $1: 500$ & Alomone Labs, Israel & ACC-034 \\
Anti-RECA-1 & $1: 100$ & Abcam, UK & ab22492 \\
Anti-NF & $1: 1000$ & Abcam, UK & ab8135 \\
Anti-Iba-1 & $1: 200$ & FUJIFILM Wako, Japan & $019-19741$ \\
Anti-laminin & $1: 50$ & Sigma & L9393 \\
Anti-GFAP & $1: 500$ & Abcam, UK & ab10062 \\
Anti-ZO-1 & $1: 50$ & Invitrogen & $40-2300$ \\
Anti-occludin & $1: 50$ & Invitrogen & $33-1500$ \\
Anti-collagen-IV & $1: 500$ & Abcam, UK & ab6586 \\
Anti-nitrotyrosine & $1: 100$ & Abcam, UK & ab183391 \\
Anti-CD-68 & $1: 200$ & Abcam, UK & ab955 \\
Anti-TGF- $\beta 1$ & $1: 100$ & Abcam, UK & ab25121 \\
Anti-CD-206 & $1: 500$ & Abcam, UK & ab64693 \\
Anti-BDNF & $1: 300$ & Alomone Labs, Israel & AGP-021 \\
Anti-NT-3 & $1: 200$ & Alomone Labs, Israel & ANT-003 \\
Anti-vWF & $1: 50$ & Millipore & AB7356 \\
Anti-ANG-1 & $1: 200$ & Abcam, UK & ab133425 \\
Anti-NG-2 & $1: 500$ & Abcam, UK & ab129051 \\
Anti- $\alpha$-SMA & $1: 200$ & Abcam, UK & ab21027 \\
Anti-connexin-43 & $1: 500$ & Abcam, UK & ab11369 \\
Anti-Tuj-1 & $1: 1000$ & Abcam, UK & ab18207 \\
Anti-growth cone & $1: 3$ & Abcam, UK & ab7762 \\
Anti-NeuN & $1: 1000$ & Abcam, UK & ab177487 \\
\hline
\end{tabular}

antibodies as given in Table 2. After $1 \mathrm{~h}$ incubation at room temperature with corresponding secondary antibodies, the blots were visualized with enhanced chemiluminescence (GE Healthcare), using the LAS 4000 biomolecular imager (GE Healthcare). The immunoblots were quantified using ImageJ software (Fiji).

\section{Immunohistochemistry and Immunofluorescence}

After SCI at T10, animals were anesthetized and perfused with $0.9 \%$ saline, followed by $4 \%$ PFA for tissue fixation at several time points as per the time points and treatments. The spinal cord at compression site was retrieved and immersed in 4\% PFA for $1 \mathrm{~d}$, and then fixed in paraffin, sectioned at $5 \mu \mathrm{m}$, dewaxed, and stained with primary antibodies overnight at $4^{\circ} \mathrm{C}$ followed by secondary antibody as given in Tables 3 and 4 . Following PBS washing, DAPI (1:500) was incubated for $10 \mathrm{~min}$. Sections were mounted in ACRYMOUNT mounting media (StatLab) and examined using a fluorescence microscope (Carl Zeiss or Leica Microsystems). Image quantification for immunofluorescence signals was performed 
Table 4. Secondary antibody information used for immunohistochemistry analysis

\begin{tabular}{llll}
\hline Secondary antibody & Dilution & Producer company & Code number \\
\hline Goat anti-rabbit AlexaFluor-488 & $1: 200$ & Abcam, UK & ab150077 \\
Goat anti-rabbit AlexaFluor-568 & $1: 200$ & Abcam, UK & ab175471 \\
Goat anti-rabbit AlexaFluor-647 & $1: 200$ & Abcam, UK & ab150083 \\
Goat anti-mouse AlexaFluor-568 & $1: 200$ & Abcam, UK & ab175473 \\
Goat anti-mouse AlexaFluor-488 & $1: 200$ & Abcam, UK & ab150117 \\
Goat anti-guinea pig AlexaFluor-488 & $1: 200$ & Abcam, UK & ab150185 \\
Chicken-anti-goat 647 & $1: 200$ & Invitrogen, USA & A-21469 \\
\hline
\end{tabular}

using Zen 3.0 [Blue edition (Carl Zeiss)]. Equal area $\left(\mathrm{nm}^{2}\right)$ was selected, channel intensities were measured, and fluorescence intensity mean value (IMV) was obtained. The fluorescence IMV was plotted as mean \pm SEM in GraphPad Prism (version 5.01, GraphPad Software).

\section{Immunocytochemistry}

For immunofluorescence microscopy, third passage hCMEC/D3 BBB cell line and HUVECs $\left(0.5 \times 10^{5}\right.$ cells/well $)$ were cultured on a sterile rat tail collagen-I (Sigma Millipore)-coated coverslip in 24-well plates. Immunocytochemistry was performed as per previously published protocol (Kumar et al., 2018b). Cells were incubated overnight at $4^{\circ} \mathrm{C}$ with antibodies directed against TRPV4 (1:100, Alomone Labs) and CD-31 (1: 100, Abcam). Secondary antibodies (1:500) were goat anti-rabbit AlexaFluor-488 and goat anti-mouse AlexaFluor-488 (Abcam). Following DAPI incubation for $10 \mathrm{~min}$, coverslips were mounted and examined using a fluorescence microscope (Carl Zeiss).

\section{Calcium imaging using two-photon fluorescence microscopy}

We evaluated the $\left[\mathrm{Ca}^{2+}\right]_{\mathrm{i}}$ inside the live rat or mouse spinal cord tissue after the injury as per the previously reported method (Kim et al., 2017). Briefly, a thin sectional tissue slice was extracted from the injured area following SCI at 3 and $8 \mathrm{HPI}$ and at 1, 3, 5, 7, 14, 21, and $28 \mathrm{DPI}$ for effective two-photon microscopy (TPM) imaging. Consequently, we incubated the spinal cord sectional slice with $10 \mu \mathrm{m} \mathrm{Ca}{ }^{2+}$ sensing unit SCa1- $\mathrm{I}_{\mathrm{REF}}$ for $40 \mathrm{~min}$ at $37^{\circ} \mathrm{C}$, and ratiometric TPM images were acquired at depths of $90-210 \mu \mathrm{m}$ for visualization of the overall $\mathrm{Ca}^{2+}$ distribution (Kim et al., 2017). The TPM images of SCa1- $\mathrm{I}_{\mathrm{REF}}$-labeled tissues were acquired with spectral confocal and multiphoton microscopes (Leica Microsystems, TCS SP8 MP) with $\times 10$ dry and $\times 40$ oil objectives, numerical aperture (NA) $=0.40$ and 1.30 as previously described (Kim et al., 2017). Ratiometric image processing and analysis were performed using MetaMorph software (Molecular Devices).

\section{Evaluation of blood-spinal cord barrier permeability}

To establish the role of TRPV4 in BSCB disruption, we examined samples from sham, injured WT, and injured TRPV4-KO mouse prepared DPI-1. The BSCB permeability was investigated with Evans blue dye extravasation according to a previous report (Kumar et al., 2018b). Briefly, at DPI-1 after SCI, $500 \mu$ l of 2\% Evans blue dye (Sigma Millipore) solution prepared in saline and administered intraperitoneally. Mouse were anesthetized $3 \mathrm{~h}$ after Evans blue dye injection and killed by intracardiac perfusion with saline. Spinal cord segment was collected and homogenized in 50\% trichloroacetic acid solution. Homogenate samples were centrifuged at $10,000 \times g$ for $10 \mathrm{~min}$, and supernatant was collected. Fluorescence intensity of Evans blue was quantified using a spectrophotometer at excitation wavelength of $620 \mathrm{~nm}$ and emission wavelength of $680 \mathrm{~nm}$ as previously described (Kumar et al., 2018b).

\section{TUNEL assay}

Paraffin sections from TRPV4 KO and WT mouse were examined for apoptotic cells at DPI-1 using an in situ death detection kit (Roche Diagnostics) as per the manufacturer's information. The images were examined using an Olympus microscope (U-TVO.63XC).

\section{Statistical analyses}

Statistical analysis was performed using GraphPad Prism (version 5.01, GraphPad Software). Data are presented as mean \pm SEM from the indicated number of experiments. The in vivo PCR data were analyzed using one-way ANOVA, followed by Tukey's test. The BMS scores and hotplate data were analyzed statistically with two-way ANOVA followed by the Bonferroni test. $p$ values $<0.05$ were considered statistically significant. The respective statistical analysis used to analyze the data is mentioned in the figure legends.

\section{Results}

TRPV4 expression increases during the early phase of SCI

We first characterized the time course of TRPV4 expression in rats at the epicenter of the SCI at 3 and $8 \mathrm{HPI}$ and at 1, 3, 5, 7, 14, 21, and 28 DPI ( $35 \mathrm{~g}$ for $5 \mathrm{~min}$ ) (Fig. 1A). TRPV4 expression was low in the uninjured spinal cord (sham condition), localized mainly to ECs, blood vessels, and neurons, and substantially increased during the early phase after SCI (Fig. 1C,F; Fig. 1-1A, available at https://doi.org/10.1523/JNEUROSCI.2035-19.2020. f1-1). The integrity of the vascular endothelium was assessed by immunostaining for rat EC antigen (RECA) (Fig. 1D; Fig. 1-1B, available at https://doi.org/10.1523/JNEUROSCI.2035-19.2020. f1-1) and angiopoietin-1 [(ANG-1), primarily expressed by pericytes] (Fig. 1-1E,F, available at https://doi.org/10.1523/ JNEUROSCI.2035-19.2020.f1-1). Neurofilament (NF), a marker of the neuronal cytoskeleton (Fig. $1 D$; Fig. 1-1B,E,F, available at https://doi.org/10.1523/JNEUROSCI.2035-19.2020.f1-1) was used to evaluate the neuronal damage after injury. ECs were lost in the injury epicenter as early as HPI-3, with some recovery by DPI-5, whereas NF immunoreactivity gradually declined with time after injury (Fig. 1D; Fig. 1-1B,D,E,F, available at https:// doi.org/10.1523/JNEUROSCI.2035-19.2020.f1-1). Intracellular calcium concentrations $\left(\left[\mathrm{Ca}^{2+}\right]_{\mathrm{i}}\right)$ were quantitated in situ at the same time points by using TPM (Fig. $1 B$ ), which revealed a biphasic response to SCI (Fig. 1 E, G; Fig. 1-1C, available at https:// doi.org/10.1523/JNEUROSCI.2035-19.2020.f1-1). SCI induced a secondary injury cascade via the production of inflammatory mediators, such as IL-6. IL-6, as assessed by qRT-PCR, showed a transient increase at early time points from HPI-3 to DPI- 1 after injury (Fig. 1H). qRT-PCR analysis showed the altered expression of protein kinase $\mathrm{C}$ and casein kinase substrate in neurons 3 (Pacsin-3), a member of the family of proteins involved in synaptic vesicular membrane trafficking that also strongly inhibits TRPV4 expression (D’hoedt et al., 2008) (Fig. 1I).

\section{Injury-dependent TRPV4 expression at the epicenter of SCI}

Next, we also investigated whether TRPV4 followed an injurydependent expression. Rats were subjected to mild (20 g/5 min), moderate ( $35 \mathrm{~g} / 5 \mathrm{~min}$ ), and severe (50 g/5 min) SCI (Fig. $2 A-C$ ). TRPV4 expression increased with the severity of the injury at the epicenter area compared with the sham group (Fig. 2D, I; Fig. 2-1A, available at https://doi.org/10.1523/JNEUROSCI.203519.2020.f2-1). The expression of TRPV4 was also increased at the rostral area in mild and severe SCI (Fig. 2D). However, the increase in $\left[\mathrm{Ca}^{2+}\right]_{\mathrm{i}}$ measured by TPM at HPI- 8 did not correspond to the severity of the injury (Fig. $2 J, H$ ). Pacsin-3 expression was declined with an increase in the injury (Fig. $2 F$ ). Assessments of inflammation (IL-6 [Fig. 2E]; HO-1, ANG-2, and TNF- $\alpha$ [Fig. $2-1 B, D, I$, available at https://doi.org/10.1523/JNEUROSCI.203519.2020.f2-1]), BSCB integrity, endothelial and vascular damage (occludin [Fig. 2G]; RECA [Fig. 2L]; neuropilin, ANG-2, and ANG-1[Fig. 2-1C,D,J, available at https://doi.org/10.1523/ JNEUROSCI.2035-19.2020.f2-1]), and neuronal damage (NF [Fig. 2L]), were congruent with the injury severity. TRPV4 immunoreactivity assessed at DPI-1 colocalized with that for the microglial marker Iba-1 and for endothelial-specific marker CD31 , indicating that ECs and microglia express TRPV4 after SCI (Fig. $2 K$ ). Furthermore, the expression of TRPV4, IL-6, and 
A
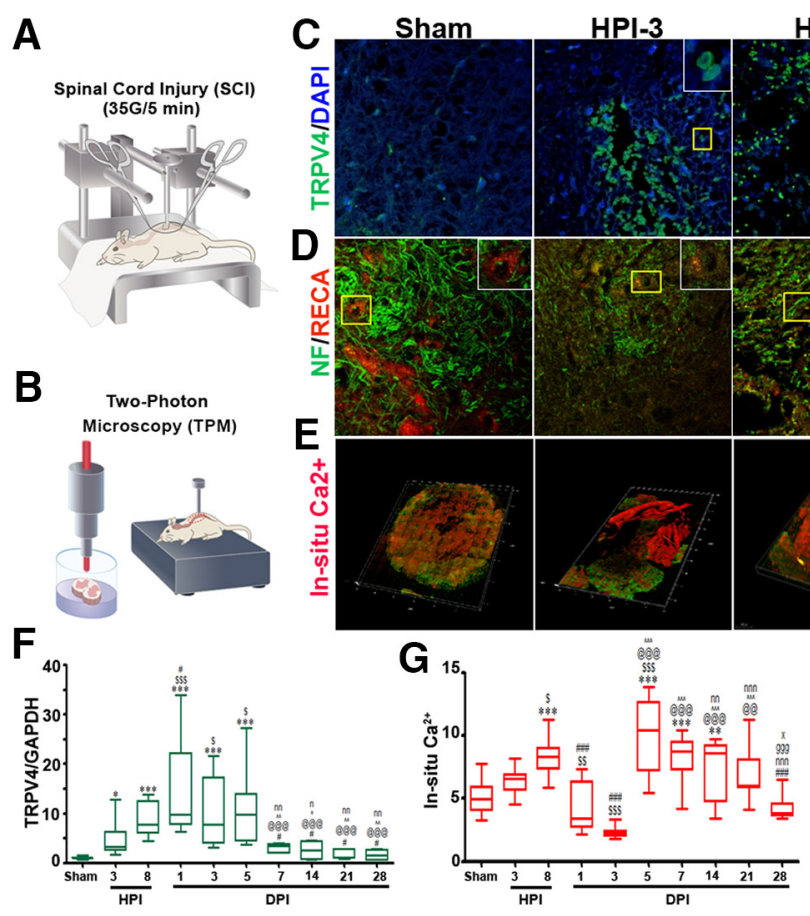

HPI-8
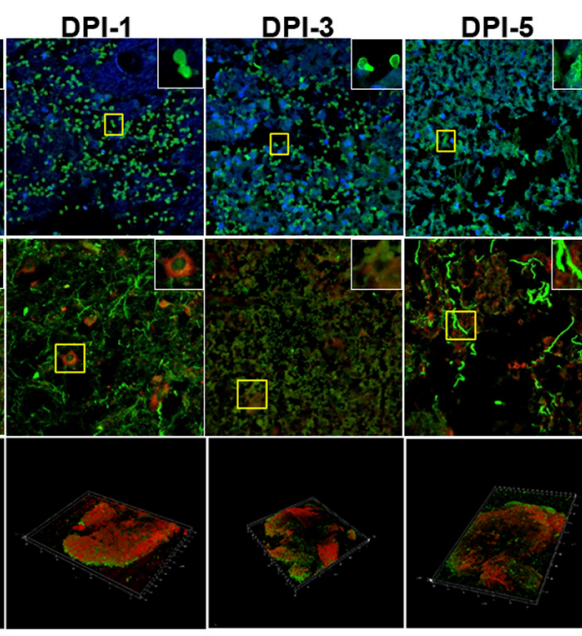

DPI-7
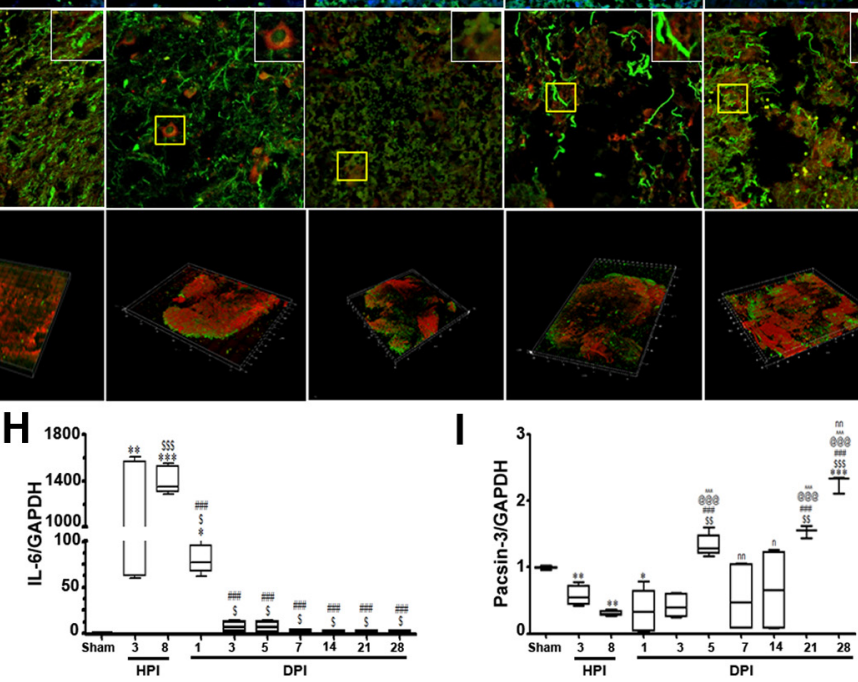

Figure 1. TRPV4 expression increased during the inflammatory/acute phase of SCI. $A$, Schematic showing SCl instrument and method. B, Schematic illustration showing TPM imaging after SCI. Representative immunohistochemistry images performed on longitudinal sections at epicenter of the damage for TRPV4 (C), and NF and RECA-1 (D) at $3 \mathrm{~h}, 8 \mathrm{~h}$, and 1,3,5, and $7 \mathrm{~d}$ after moderate static compression ( $35 \mathrm{~g} / 5 \mathrm{~min}$ ) SCI (Carl Zeiss microscope, 3 fields/slide, $n=3 /$ time point). SCI rat sectional slice labeled with $10 \mu \mathrm{m} \mathrm{SCa1-IREF} \mathrm{for} 40 \mathrm{~min}$. In situ Ca ${ }^{2+}$ levels were determined in the transverse spinal cord using TPM at similar time points after $\mathrm{SCl}$ at the epicenter of the damage. $\boldsymbol{E}$, Two-photon excited fluorescence was collected using $750 \mathrm{~nm}$ excitation and emission windows at $400-430 \mathrm{~nm}$ (Ch1) and $500-600 \mathrm{~nm}$ (Ch2). Total RNA was prepared from the epicenter of the damage collected $3 \mathrm{~h}, 8 \mathrm{~h}$, and 1, 3, 5, 7, 14, 21, and $28 \mathrm{~d}$ after SCl to determine the expression of TRPV4 (F), IL-6 $(\boldsymbol{H})$, and Pacsin-3 (I) ( $n=4-6$ /time point, performed in triplicates). G, Quantification of in situ $\mathrm{Ca}^{2+}$ levels. GAPDH was used as internal controls for qRT-PCR. Data are mean \pm SEM. ${ }^{*} p<0.05,{ }^{* *} p<0.01,{ }^{* * *} p<0.001$ compared with sham group. ${ }^{\$} p<0.05,{ }^{\$ \$ \$} p<0.001$ compared with HPI-3. ${ }^{\#} p<0.05$ compared with HPI-8. ${ }^{@} p<0.05$, ${ }^{@ @ ~} p<0.01$, ${ }^{{ }^{*} @ p} p<0.001$ compared with DPI-1. ${ }^{\wedge} p<0.05,{ }^{\wedge} p<0.01$ compared with DPI-3. ${ }^{{ }^{n} p}<0.05,{ }^{n n} p<0.01$ compared with DPI-5. ${ }^{9} p<0.05,{ }^{g 9 g} p<0.01$ compared with DPI-7. ${ }^{\mathrm{x}} p<0.05$, ${ }^{\mathrm{xxx}} p<0.01$ compared with DPI-21 by one-way ANOVA Tukey's post test.

Pacsin-3 was altered by hemisection of the spinal cord; however, the increase in TRPV4 was to a lesser extent than that with compression SCI (Fig. 2M-O). Together, these results suggest that TRPV4 expression and related parameters are associated with the severity of compression injury.

\section{Activation of TRPV4 promotes endothelial damage, whereas inhibition is protective}

To evaluate the effect of TRPV4 activation on ECs and the BSCB, we incubated hCMEC/D3 BBB cells, which have basal expression of TRPV4, for $24 \mathrm{~h}$ with a TRPV4 agonist ( $1 \mu \mathrm{M}$ GSK1016790A [GSK]) or antagonist (10 $\mu \mathrm{M} \mathrm{RN}-1734)$, which results in increased or decreased TRPV4 expression, respectively (Fig. $3 A, B$ ). The CD-31 immunoreactivity to assess the integrity/status of the ECs was reduced by TRPV4 activation; this reduction was mitigated by pretreatment with the antagonist (Fig. $3 \mathrm{~A}, \mathrm{C}$ ). Accordingly, TRPV4 agonist or antagonist results in increased or decreased TRPV4 expression, respectively, in HUVECs (Fig. $3 D, E)$. Similar to hCMEC/D3 BBB cells, endothelial integrity/ status, as measured by von Willebrand factor (vWF) immunoreactivity, was altered by TRPV4 activation, and this was prevented by the TRPV4 antagonist (Fig. $3 D, F$ ). The expression of TJ markers zonula occludens-1 (ZO-1), ZO-2, and claudin-1 was attenuated by GSK $(1 \mu \mathrm{M})$, with a prominent effect observed for ZO-2 and claudin-1; however, the TRPV4 antagonist RN-1734 (10 $\mu \mathrm{M})$ or RN-1734 treatment before GSK either maintained or increased the expression of the TJ markers (Fig. 3-1A, available at https:// doi.org/10.1523/JNEUROSCI.2035-19.2020.f3-1). To assess the effect of TRPV4 activation in vivo, GSK (50 pM) was injected directly into the spinal cords of rats. We examined samples from uninjured sham and GSK-treated animals after $28 \mathrm{~d}$ as well as from vehicle and GSK-treated animals at DPI-28. SCI causes centralized fibrotic scars surrounded by a reactive glial scar at the epicenter. Damaged vessels immunoreactive for laminin, a component of the basal lamina, were readily identified at DPI-28 (Fig. $3 G$ ). A single injection of GSK changed/damaged the morphology of laminin structures (J- or T-shaped under normal conditions) and RECA-stained vessels (Fig. 3G,J). The basal lamina also comprises collagen IV, and the normal uniform distribution was altered by GSK injection; a dense collagen IV meshwork was observed at DPI-28 in animals treated with vehicle or GSK (Fig. 3-1 N, O, available at https://doi.org/10.1523/JNEUROSCI.203519.2020.f3-1). Immunoreactivity for ANG-1, a CNS endothelium neurotrophin, was decreased after GSK treatment (Fig. 3-1 N, O, available at https://doi.org/10.1523/JNEUROSCI.203519.2020.f3-1).

We also evaluated the effect of TRPV4 activation alone or with injury at day 28. Interestingly, GSK injections only produced an increase in microglial cells (as determined by Iba-1 immunoreactivity) but not in reactive astrocytes (as determined by GFAP immunoreactivity) (Fig. $3 H, K$ ). Immunoreactivity for the axonal marker NF revealed significant loss with GSK injection and extensive damage in injured spinal cords compared with that in the sham group (Fig. $3 I, L$ ). Additionally, blood infiltration following BSCB disruption after SCI initiates a secondary injury cascade via the production of inflammatory mediators, such as TNF- $\alpha$, IL-6, and inducible nitric oxide synthase. As the activation of TRPV4 appeared to damage ECs, we examined the effect 
A
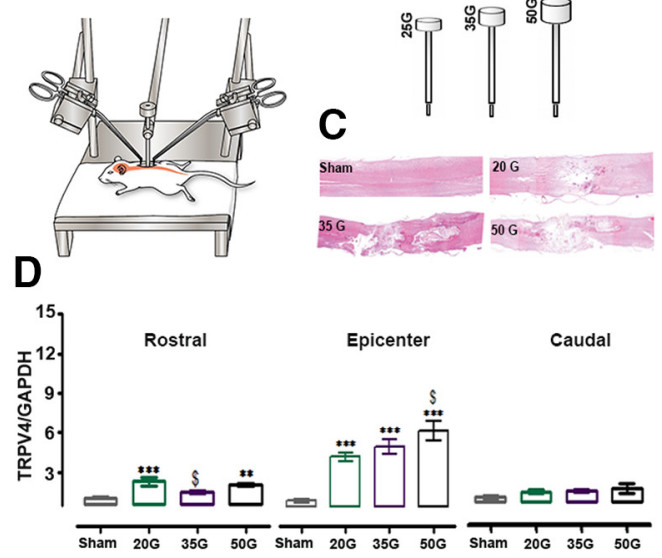

E

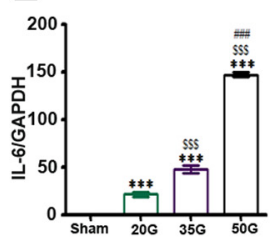

G

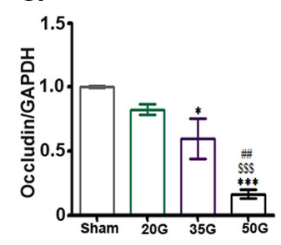

B

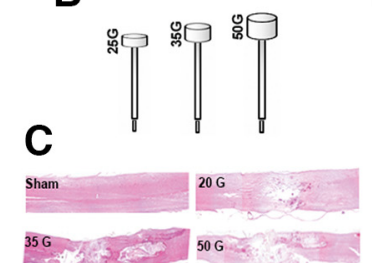

$F$

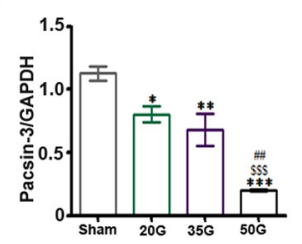

H

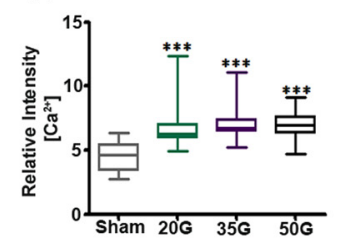

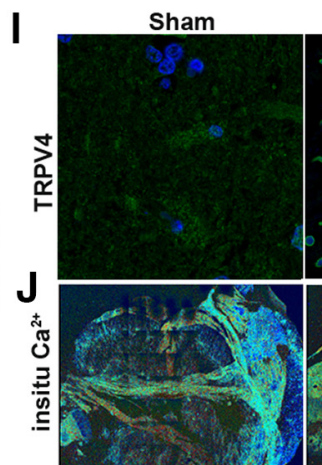

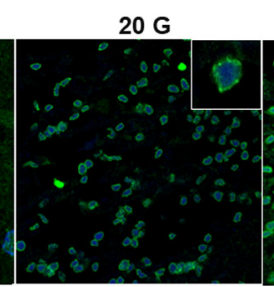

$20 \mathrm{G}$

$35 \mathrm{G}$

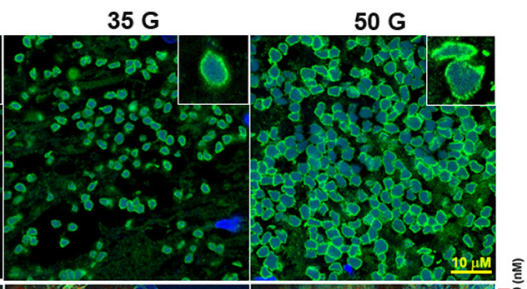

$50 \mathrm{G}$
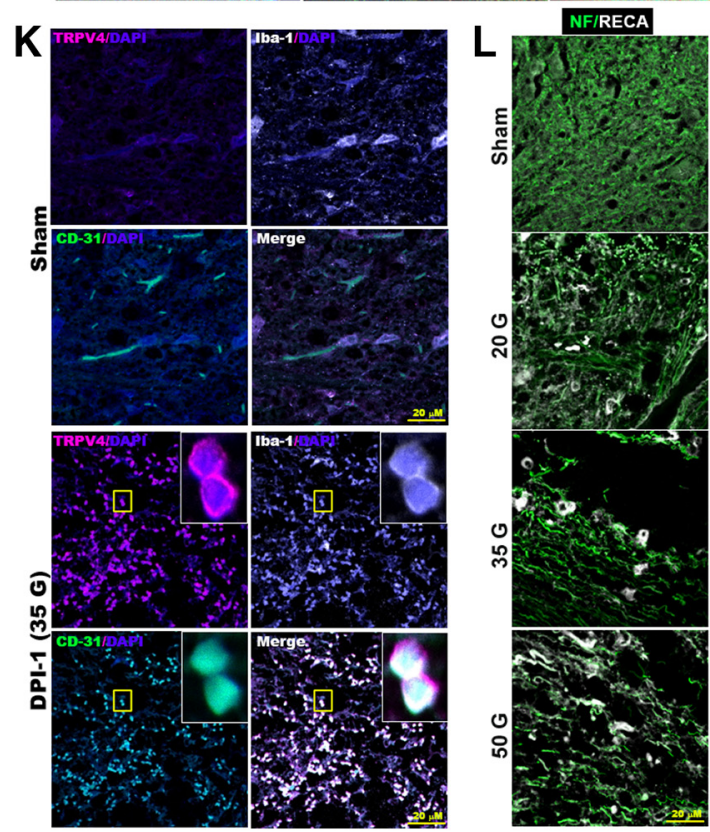

M
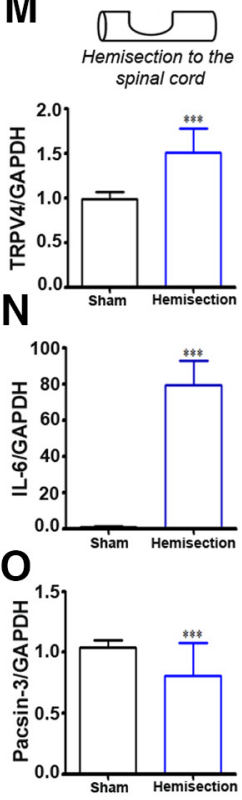

Figure 2. TRPV4 expression is linked with injury severity and inflammation. Schematic showing method for injury-dependent expression and impounder of different weight $(A, B)$. H\&E staining was performed on the longitudinal section after mild $(20 \mathrm{~g} / 5 \mathrm{~min})$, moderate $(35 \mathrm{~g} / 5 \mathrm{~min})$, and severe $(50 \mathrm{~g} / 5 \mathrm{~min})$ injury (C). Total RNA was prepared from spinal cord tissues at the rostral, epicenter, and caudal of the damage collected at $1 \mathrm{~d}$ after SCI (mild, moderate, and severe compression) to determine the expression of TRPV4 (D), IL-6 (E), Pacsin3 (F), and occludin (G). RNA expression was determined at the epicenter at $1 \mathrm{~d}$ after $\mathrm{SCI}$ (mild, moderate, and severe) ( $n=2$ or $3 /$ group performed in triplicates). TRPV4 $(\boldsymbol{I})$ and NF and RECA-1 (L) IHC was performed after mild ( $20 \mathrm{~g})$, moderate $\left(35 \mathrm{~g}\right.$ ), and severe $(50 \mathrm{~g})$ injury (Carl Zeiss microscope, 3 fields/slide, $n=3 /$ time point). In situ $\mathrm{Ca}^{2+}$ levels were determined using TPM at $8 \mathrm{~h}$ after SCl (mild, moderate, and severe) at the epicenter of the damage $(\boldsymbol{J})$. Quantification of in situ $\mathrm{Ca}^{2+}$ levels $(\boldsymbol{H})$. Colocalization of TRPV4 with $(D-31$, an endothelial marker, and lba-1, a microglial marker $(\boldsymbol{K})$. Total RNA was prepared from spinal cord tissues after spinal cord hemisection to determine the expression of TRPV4 (M), IL-6 ( $\boldsymbol{N})$, and Pacisn3 ( $\mathbf{0})$ ( $n=4$ or 5/group). GAPDH was used as internal controls for qRT-PCR. Data are mean \pm SEM performed in triplicates. ${ }^{*} p<0.05,{ }^{* *} p<0.01,{ }^{* * *} p<0.001$ compared with sham group. ${ }^{\$} p<0.05,{ }^{\$ \$} p<0.01,{ }^{\$ \$ \$} p<0.001$ compared with 20 g injury group. ${ }^{\#} p<0.05$, ${ }^{\# \#} p<0.01$, $\#$ \#\#\# $<0.001$ compared with $35 \mathrm{~g}$ injury group by one-way ANOVA Tukey's post test.

of TRPV4 inhibition on BSCB integrity, inflammation, and $\mathrm{Ca}^{2+}$ levels during the early phase after SCI, when there is peak TRPV4 expression. Samples from sham, injured vehicle-treated, and injured RN-1734-treated ( $5 \mathrm{mg} / \mathrm{kg}$, i.p.) animals were analyzed at DPI-1. Treatment with RN-1734 significantly inhibited TRPV4 expression attenuated SCI-induced inflammatory cytokines and prevented the loss of the TJ proteins occludin and ZO-1 after injury (Fig. 3 M,N,P, Q,S-W; Fig. 3-1 H-M, available at https:// doi.org/10.1523/JNEUROSCI.2035-19.2020.f3-1). In addition, treatment with RN-1734 significantly reduced the SCI-induced calcium release as determined by $\mathrm{Ca}^{2+}$ imaging at HPI-8 (Fig. $3 O, R)$.

TRPV4 KO mice have less endothelial damage and inflammation

On the basis of the above-described results, we hypothesized that the ablation of TRPV4 signaling would protect ECs and preserve BSCB integrity. To test this, we induced SCI (20 g/ $1 \mathrm{~min})$ at $\sim \mathrm{T} 10$ in TRPV4 KO and WT mice at DPI-1 (Fig. 4A). Evans blue extravasations consistent with an increase in barrier permeability were observed in WT mice but not in TRPV4 KOs (Fig. 4B,C). The loss of TJ proteins, such as occludin, ZO-1, ZO-2, and claudin-1, did not occur in TRPV4 KO mice (Fig. 4D, L, Q; Fig. 4-1A,C-F, available at https://doi.org/10.1523/JNEUROSCI.203519.2020.f4-1), and ECs were preserved, as determined by higher CD-31 levels (Fig. 4-1 A, G, available at https://doi.org/10.1523/ JNEUROSCI.2035-19.2020.f4-1), accompanied by an attenuation of the increase in VEGF expression after injury (Fig. 4E). The $\sim 100 \mathrm{kDa}$ band for TRPV4 was barely detectable in the KO mice compared with the WT after injury (Fig. 4-1 $A, B$, available at https://doi.org/10.1523/JNEUROSCI.2035-19.2020.f4-1). Proinflammatory cytokine and chemokine production increased in WT mice after SCI compared with that in sham controls, and this was significantly attenuated in TRPV4 KO mice (Fig. $4 F-K$ ).

We performed TUNEL assays to assess apoptosis after SCI. At DPI-1, apoptotic cells were present at the epicenter in both WT 


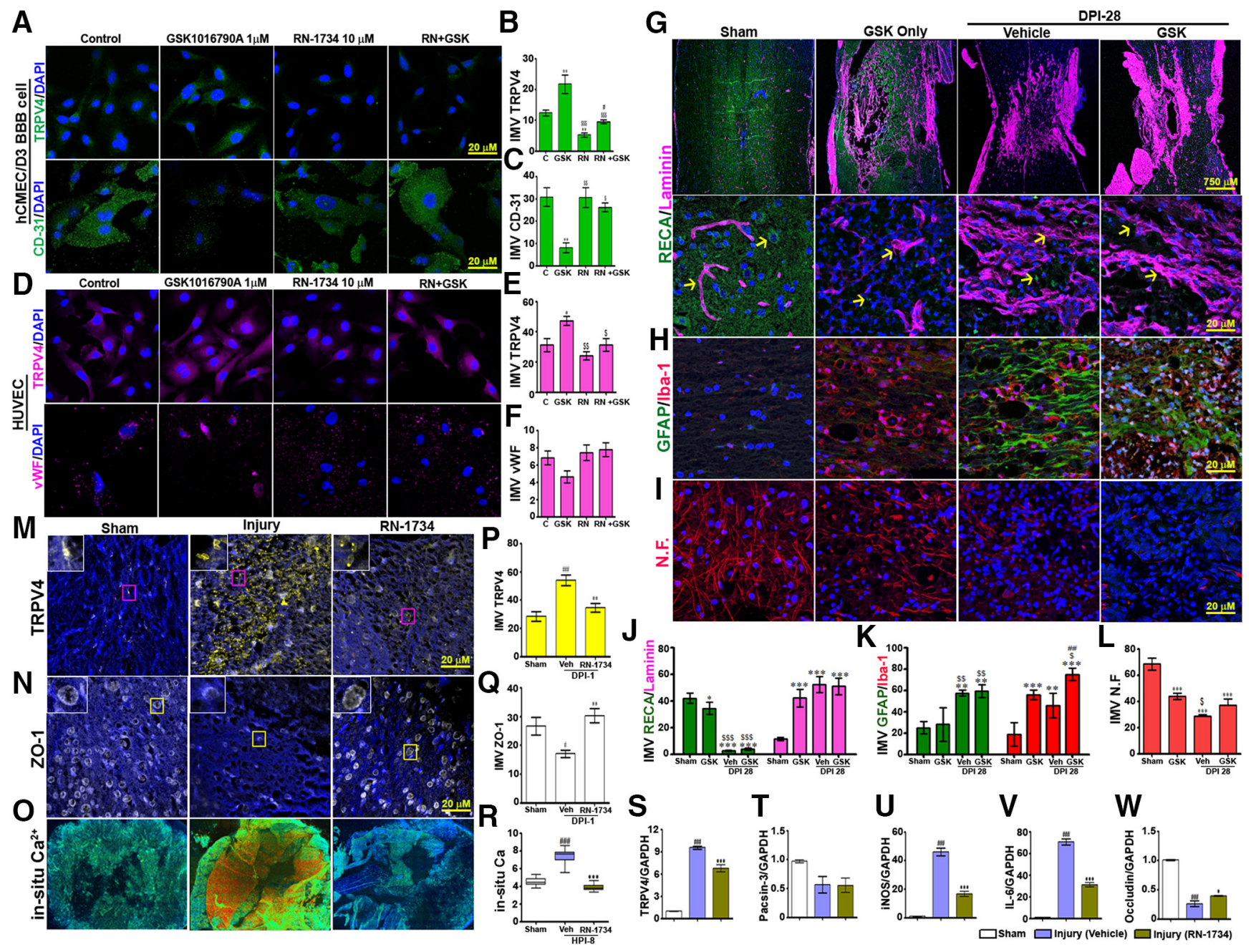

Figure 3. TRPV4 activation causes endothelial remodeling/damage, whereas TRPV4 inhibition protects SCl-induced endothelial damage. TRPV4 and CD-31 (A) immunocytochemistry was performed on fixed hCMEC/D3 BBB cell line as described in Materials and Methods. Quantification of TRPV4 and CD-31 fluorescence (B,C). TRPV4 and vWF immunocytochemistry was performed on fixed HUVECs $(\boldsymbol{D})$ and its quantification $(\boldsymbol{E}, \boldsymbol{F})$. GSK1016790A (50 pmol, $10 \mu \mathrm{l})$ was injected into the spinal cord of the rats as mentioned in Materials and Methods. Samples from sham, GSK1016790A, vehicle (injury), or GSK1016790A (injury) were prepared $28 \mathrm{~d}$ after injection/injury. Representative images of laminin (magenta) and RECA-1 (G; green), GFAP (H; green), lba-1 (H; red), and NFs (I; red). $J-L$, Bar charts represent the fluorescence IMV for corresponding protein as per randomly selected field area at the injury epicenter ( 3 fields $/$ lide, $n=3 / \mathrm{group}$ ). Samples from sham or injured untreated (injury) or after RN-1734 (5 mg/kg) treatment were prepared $1 \mathrm{~d}$ after moderate injury ( $35 \mathrm{~g} / 5 \mathrm{~min})$. Representative transverse section of TRPV4 $(\boldsymbol{M})$ and Z0-1 (N) ( 3 fields $/ \mathrm{slide}, n=3)$ and fluorescence IMV for corresponding protein $(\boldsymbol{P}, \mathbf{Q})$. Total RNA from sham, vehicle (injury), or RN-1734-treated ( $5 \mathrm{mg} / \mathrm{kg}$, i.p.) samples was prepared DPI- 1 after injury. RT-PCR results are showing relative expression levels of TRPV4 $(\boldsymbol{S})$, Pacsin $3(\boldsymbol{T})$, inducible nitric oxide synthase $(\boldsymbol{U}), \mathrm{IL}-6(\boldsymbol{V})$, and occludin $(\boldsymbol{W}) . I n$ situ $\mathrm{Ca}^{2+}$ levels were determined in the transverse spinal cord using TPM at $8 \mathrm{~h}$ after SCl at the epicenter of the damage (0). Quantification of in situ $\mathrm{Ca}^{2+}$ levels $(\boldsymbol{R})$. Data are mean $\pm \operatorname{SEM}\left(n=2\right.$ or $3 /$ group performed in triplicates). ${ }^{*} p<0.05,{ }^{* *} p<0.01$, compared with sham group. ${ }^{\$} p<0.05,{ }^{\$ \$} p<0.01$, ${ }^{\$ \$ \$} p<0.001$ compared with GSK group. ${ }^{\#} p<0.05(\boldsymbol{B}, \boldsymbol{C}, \boldsymbol{E}) .{ }^{\#} p<0.05$, ${ }^{\# \#} p<0.01,{ }^{\# \# \#} p<0.001$ compared with sham group. ${ }^{*} p<0.05$, ${ }^{* *} p<0.01$, compared with injury group $(\boldsymbol{P}-\boldsymbol{W}) .{ }^{*} p<0.05,{ }^{* *} p<0.01,{ }^{* * *} p<0.001$ compared with sham group. ${ }^{\$} p<0.05,{ }^{\$ \$} p<0.01,{ }^{\$ \$ \$} p<0.001$ compared with GSK group (J-L) by one-way ANOVA Tukey's post test.

and KO mice; however, the percentages of TUNEL-positive cells and the amount of caspase-3 were much lower in TRPV4 KO mice than in WT mice (Fig. $4 L, M$; Fig. 4-1 $A, L$, available at https://doi.org/10.1523/JNEUROSCI.2035-19.2020.f4-1). ERK, JNK, and AKT expression was not significantly different between TRPV4 KO and WT mice, whereas KO mice showed a reduction in p38 expression (Fig. 4-1 $A, H-K$, available at https://doi.org/ 10.1523/JNEUROSCI.2035-19.2020.f4-1). TPM imaging at HPI-8 revealed that SCI-induced $\left[\mathrm{Ca}^{2+}\right]_{\mathrm{i}}$ was inhibited in TRPV4 KO mice (Fig. 4N,O).

\section{Reduced scarring in TRPV4 KO mice after SCI}

To further assess the endothelial protective effects of TRPV4 ablation on scarring, we assessed scarring (glial and fibrotic) $28 \mathrm{~d}$ after SCI. Whereas the lesions of WT animals contained large amounts of laminin and collagen IV, hallmarks of the fibrotic scars thought to hinder axon regeneration, the amounts in lesions of TRPV4 KO mice were much lower (Fig. 5A, B, G,I). The expression of GFAP indicative of glial formation was higher at DPI-28 in WT than in TRPV4 KO mice, whereas the expression of NF, a marker for neuronal cytoskeleton, was higher at DPI-28 in TRPV4 KO than in WT mice, suggesting that KO mice had attenuated glial scarring and better neuronal protection (Fig. $5 C, K, M, N, Q)$. Similarly, immunostaining for Iba-1 to detect resident microglia and infiltrating monocyte-derived macrophages showed significantly reduced expression in TRPV4 KO mice compared with that in WT mice (Fig. 5D, H, M, O). By contrast, the expression of CD-206, a marker for M2 macrophages, was increased in TRPV4 KO mice (Fig. $5 E, J$ ). Immunoreactivity for TGF- $\beta$, a key mediator of fibrotic scarring, and CD-68, a 
A

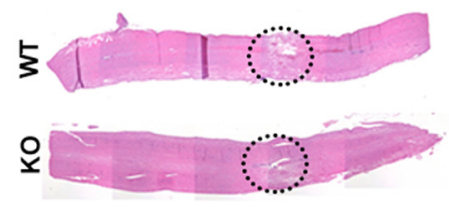

B

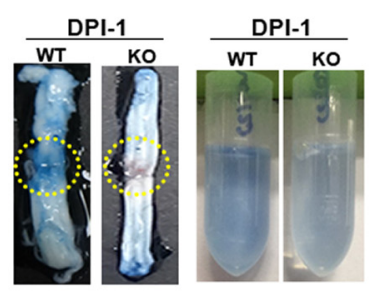

D

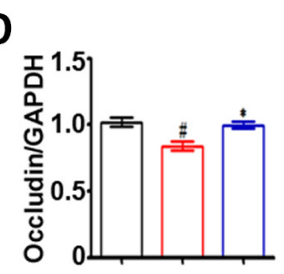

H

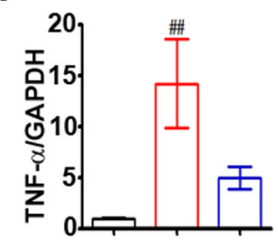

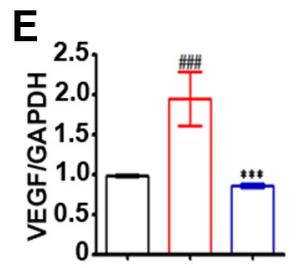

F

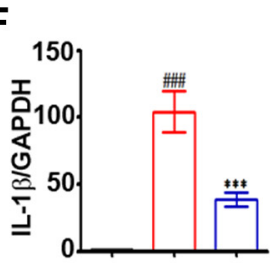

J

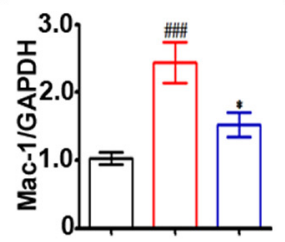

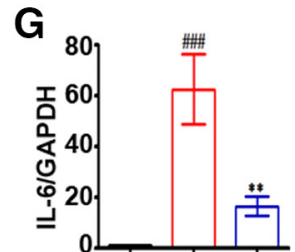

K
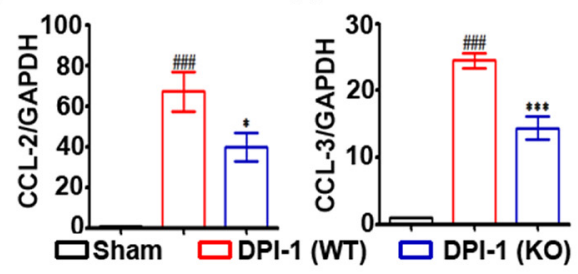

DPI-1
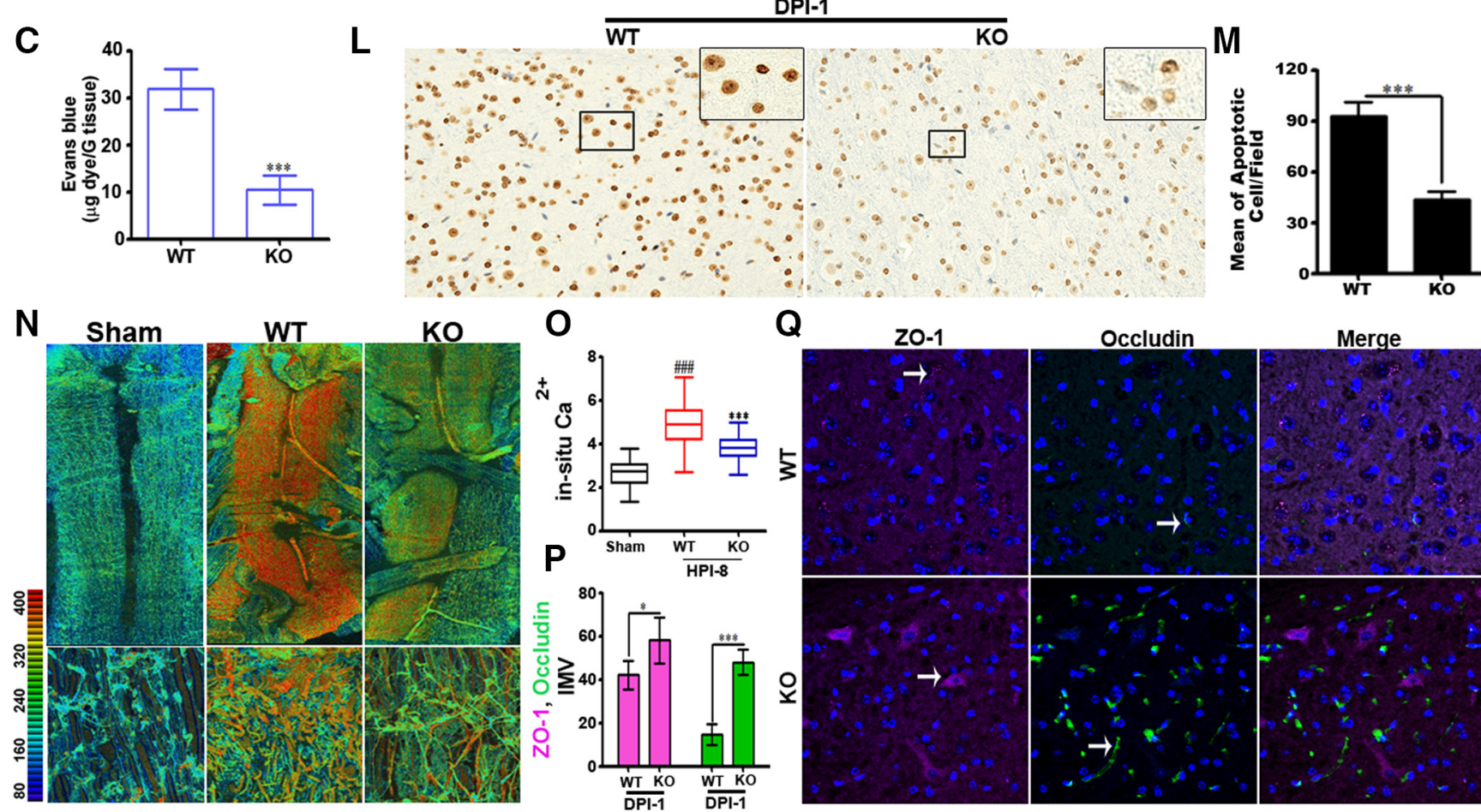

0

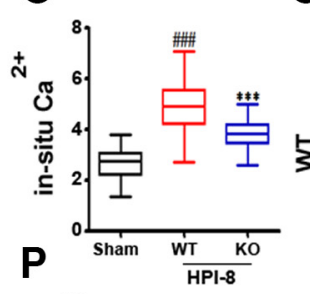

Q
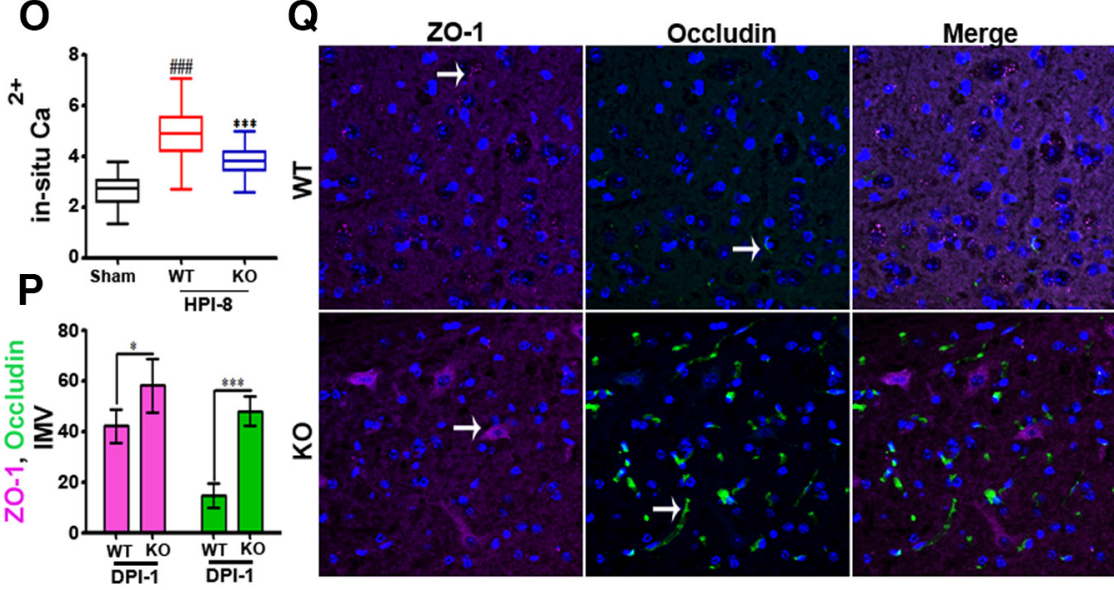

Figure 4. Reduced endothelial damage and inflammation after SCl in TRPV4 K0 mice. Representative images of H\&E staining at DPI-1 after SCI ( $A$ ). Representative whole spinal cords show Evans blue dye extravasation of the spinal cord 1 d after $S C I$ (B) and its quantification (C). Total RNA from sham (black bar), wild (red bar), or TRPV4 KO (blue bar) samples was prepared DPI-1 after the injury as described in Materials and Methods. RT-PCR results show relative expression levels of occludin (D), VEGF (E), IL-1 $\beta(\boldsymbol{F})$, IL-6 (G), TNF- $\alpha(\boldsymbol{H})$, macrophage-1 antigen (Mac-1) (I), chemokine (C-C motif) ligand 2 (CCL-2) $(J)$, and chemokine (C-C motif) ligand 3 (CCL-3) $(K)$ after injury $(n=2$ or 3/group performed in triplicates). GAPDH was used as internal controls for qRT-PCR. TUNEL assay was performed at DPI-1 (L). Quantification of TUNEL-positive cells $(\boldsymbol{M})$. SCI-induced mouse sectional slice labeled with $10 \mu \mathrm{M}$ SCa1-IREF for 40 min. In situ $\mathrm{Ca}^{2+}$ levels were determined in the longitudinal spinal cord using TPM at $8 \mathrm{~h}$ after SCl at the epicenter of the damage. Two-photon excited fluorescence was collected using $750 \mathrm{~nm}$ excitation and emission windows at $400-430 \mathrm{~nm}$ (Ch1) and 500-600 nm and its quantification (Ch2) $(\boldsymbol{N}, \mathbf{O})$. Representative images for Z0-1 (magenta) and occludin ( $\boldsymbol{Q} ;$ green) and fluorescence IMV for corresponding protein $(\boldsymbol{P})$. $\# \# \# \mathbf{p}<0.001$ compared with sham group. ${ }^{*} p<0.05,{ }^{* *} p<0.01,{ }^{* * *} p<0.001$ compared with WT-injury group $(\boldsymbol{D}-\boldsymbol{K}, \boldsymbol{O})$ by one-way ANOVA Tukey's post test. ${ }^{*} p<0.05,{ }^{* *} p<0.01,{ }^{* * *} p<0.001$ vs WT-injury group $(C, M, P)$ by unpaired $t$ test.

marker for activated macrophages, was significantly lower in TRPV4 KO mice than in WT mice (Fig. $5 F, L$ ). The expression of connexin-43, an abundant gap junction protein in the CNS, was markedly higher in WT mice than in TRPV4 KO mice, whereas CD-31, which makes up a large portion of EC intercellular junctions, was higher in TRPV4 KO mice (Fig. $5 M, P, R$ ).

TRPV4 KO mice show improved functional recovery and neuroprotection

To evaluate the functional consequences of TRPV4 ablation, we assessed gross locomotor function in TRPV4 KO and WT mice using the BMS to assess open field hindlimb locomotion (Basso et al., 2006). TRPV4 KO mouse spinal cord was better preserved compared with WT as determined by H\&E staining (Fig. 6A). Mice developed paraplegia after SCI, corresponding to a low BMS score at DPI-1-3, but demonstrated evidence of modest improvement as early as DPI-7 (Fig. 6B). The BMS scores over 4 weeks ranged from $0.30 \pm 0.48$ to $4.7 \pm 2.0$ for WT mice and from $0.50 \pm 0.71$ to $7.00 \pm 2.00$ for TRPV4 KO mice, with TRPV4 ablation associated with faster recovery and better motor coordination in comparison with that for WT (Fig. 6B). The performance of sham control mice remained unchanged throughout the testing period (data not shown). As nociception is also affected after SCI, we evaluated the effect of TRPV4 dele- 

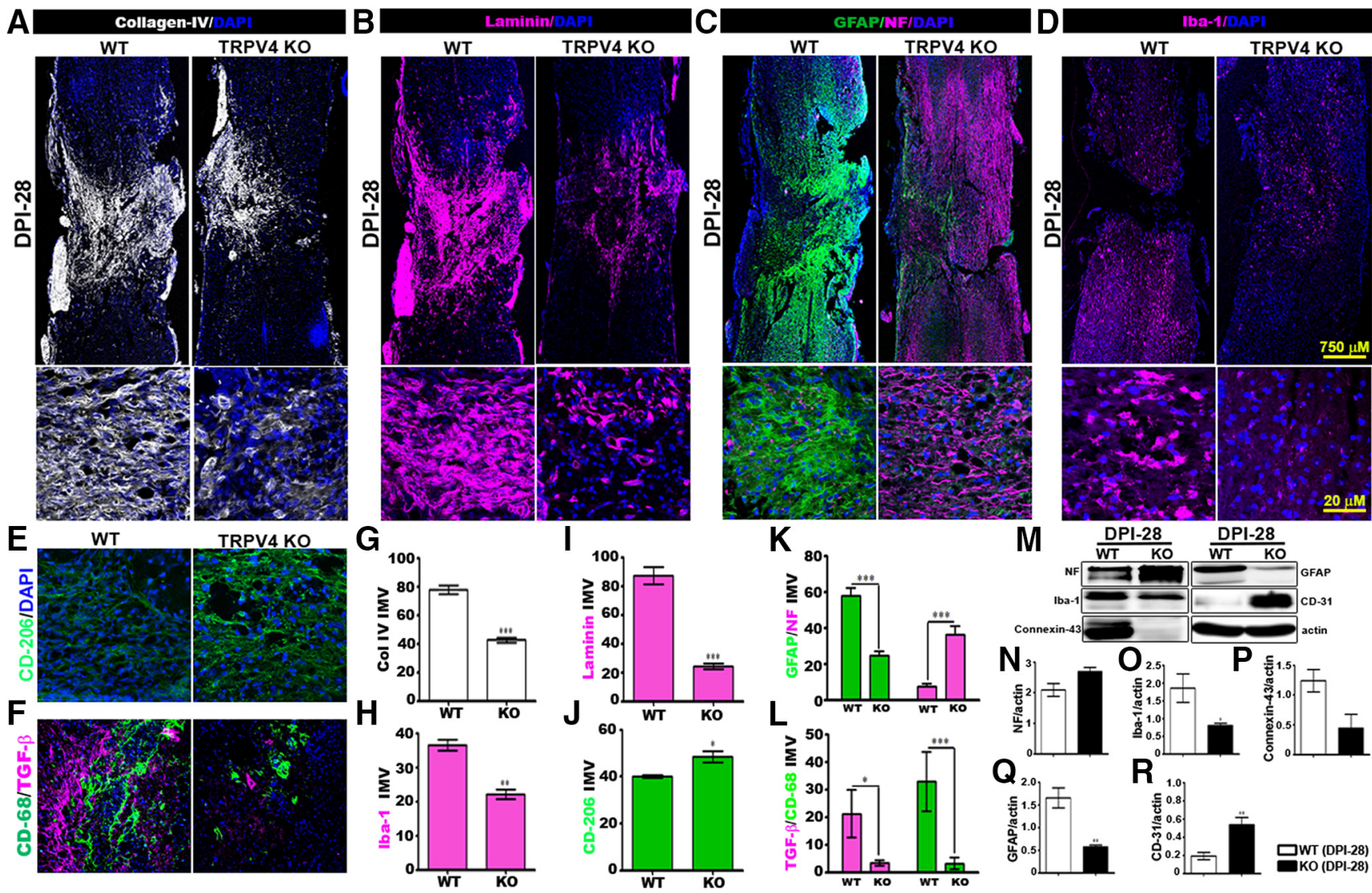

$20 \mu \mathrm{M}$

0

Figure 5. TRPV4 KO mice exhibit less fibrotic and glial scarring after SCI. Samples from WT (injury) or TRPV4 K0 (injury) were prepared at DPI-28 as described in Materials and Methods. Representative merges images (longitudinal) for Collagen IV ( $\boldsymbol{A}$; white), laminin ( $\boldsymbol{B}$; magenta), GFAP ( $\boldsymbol{C}$; green), NF (C; magenta), lba-1 (D; magenta), CD-206 (E; green), CD-68 ( $\boldsymbol{F}$, green), and TGF- $\beta 1$ ( $\boldsymbol{F}$; magenta) at DPI-28. Bar charts represent the fluorescence IMV for Collagen IV $(\boldsymbol{G})$, Iba-1 $(\boldsymbol{H})$, laminin $(\boldsymbol{I})$, CD-206 $(\boldsymbol{J})$, GFAP and NF $(\boldsymbol{K})$, and TGF- $\beta 1$ and $(\mathrm{D}-68(\boldsymbol{L})$ as per randomly selected field area at the injury epicenter ( 3 fields/slide, $n=3$ /group). $\boldsymbol{M}$, Western blots of NFs, Iba-1, Connexin-43, GFAP, and CD-31 expression at 28 dafter injury. Quantification of immunoblot for NF ( $N$ ), Iba-1 (0), Connexin-43 (P), GFAP (Q), and (D-31 (R) was performed using ImageJ. Actin was used as internal controls for Western blot ( $n=2$ or $3 /$ group). Data are mean \pm SEM. ${ }^{*} p<0.05$, ${ }^{* *} p<$ $0.01,{ }^{* * *} p<0.001$ vs WT-injury group by unpaired $t$ test.

tion on SCI-induced pain using the hotplate test (Fig. 6C). After $\mathrm{SCI}$, animals exhibited thermal hypersensitivity (decrease in reaction time) on days 1, 3, 7, and 14 but not at 21 and $28 \mathrm{~d}$ (Fig. $6 D$ ). This hypersensitivity was significantly attenuated at DPI-1, DPI-3, and DPI-7 in TRPV4 KO mice. Immunoreactivity for ANG-1, BDNF, and neurotrophin 3 (NT-3) neurotrophic factors, which are primary mediators of axonal and neuronal plasticity and regeneration after SCI, was also greater in TRPV4 KO mice than in WT mice after SCI (Fig. 6E, F). We also assessed the effects of TRPV4 deletion on neuroprotection and angiogenesis after SCI. Immunohistochemistry of microvessels in spinal cord sections revealed that expression of vWF (Fig. $6 G$ ) and neural/ glial antigen 2 (NG-2) and $\alpha$-smooth muscle actin ( $\alpha$-SMA) (Fig. $6 \mathrm{H}$ ) was higher in TRPV4 KO mice after injury than in WT mice. Accordingly, immunoreactivity for growth cones was more evident in axons in TRPV4 KO mice than in WT mice (Fig. 6J), which was accompanied by greater immunoreactivity for neuronal markers TuJ1 and NeuN, indicating better neuronal protection in TRPV4 KO mice (Fig. 6I,J). These results suggest that abrogation of TRPV4 signaling is neuroprotective during SCI.

\section{Discussion}

In the present study, we establish that TRPV4, a nonselective cation channel expressed by astrocytes and neurons (Ryskamp et al., 2014; Shibasaki et al., 2014), is a crucial determinant of endothelial disruption and the pathology after SCI. We show that SCI induces the expression of TRPV4 at earlier time points; however, the free $\left[\mathrm{Ca}^{2+}\right]_{\mathrm{i}}$ level follows a biphasic increase. However, there may be various mechanisms by which SCI produces these effects. (1) The increase in TRPV4 expression may be induced by mechanical stimulation as a result of cell swelling, as TRPV4 is also a volume-sensitive mechanosensor (Nilius et al., 2001; Shi et al., 2013). (2) Most $\mathrm{Ca}^{2+}$-permeable channels show some feedback regulation by $\mathrm{Ca}^{2+}$ to prevent deleteriously significant increases in $\left[\mathrm{Ca}^{2+}\right]_{\mathrm{i}}$ or to shape the time course of channel activity, and experimental evidence shows that TRPV4 is tightly regulated by $\left[\mathrm{Ca}^{2+}\right]_{\mathrm{i}}$ (Strotmann et al., 2003). (3) TRPV4 is highly sensitive to changes in extracellular osmolarity, as reductions in the extracellular osmolarity result in increases in $\left[\mathrm{Ca}^{2+}\right]_{\mathrm{i}}$ and membrane currents and osmolarities $>300 \mathrm{mosmol} / \mathrm{L}$ decrease both $\left[\mathrm{Ca}^{2+}\right]_{i}$ and currents (Strotmann et al., 2000). (4) $\mathrm{Ca}^{2+}$ is involved in both the decaying phase and the activation phase of TRPV4 (Plant and Strotmann, 2006). Traumatic SCI can result in contusion, compression, and stretch injury. Both compression and contusion models simulate the biomechanics and neuropathology of human injury (Sharif-Alhoseini et al., 2017). In the current study, we used clinically relevant SCI via controlled mechanical compression (Yu et al., 2013; Ropper et al., 2015). The advantage of the current method is that delivered force is precisely known at the time of application compared with other compression models. One limitation of the current methods is the variability in 
A

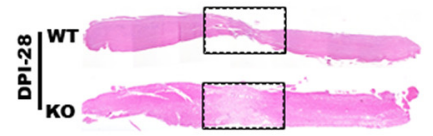

C

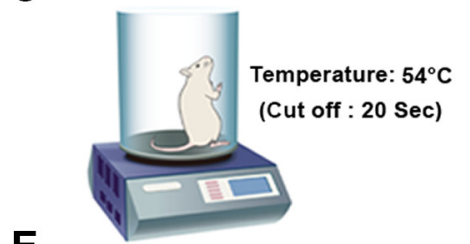

E

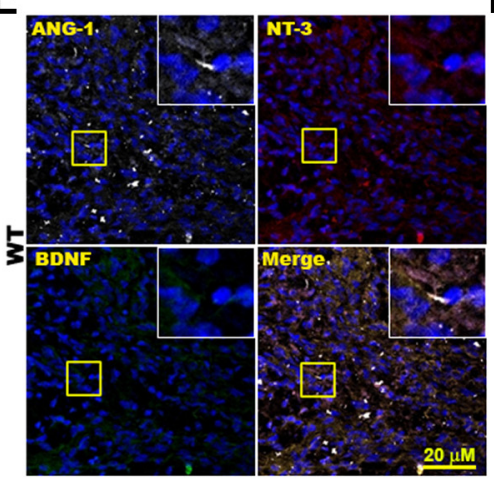

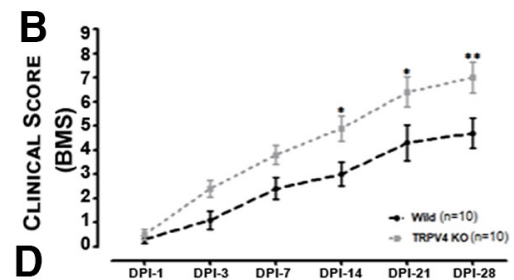
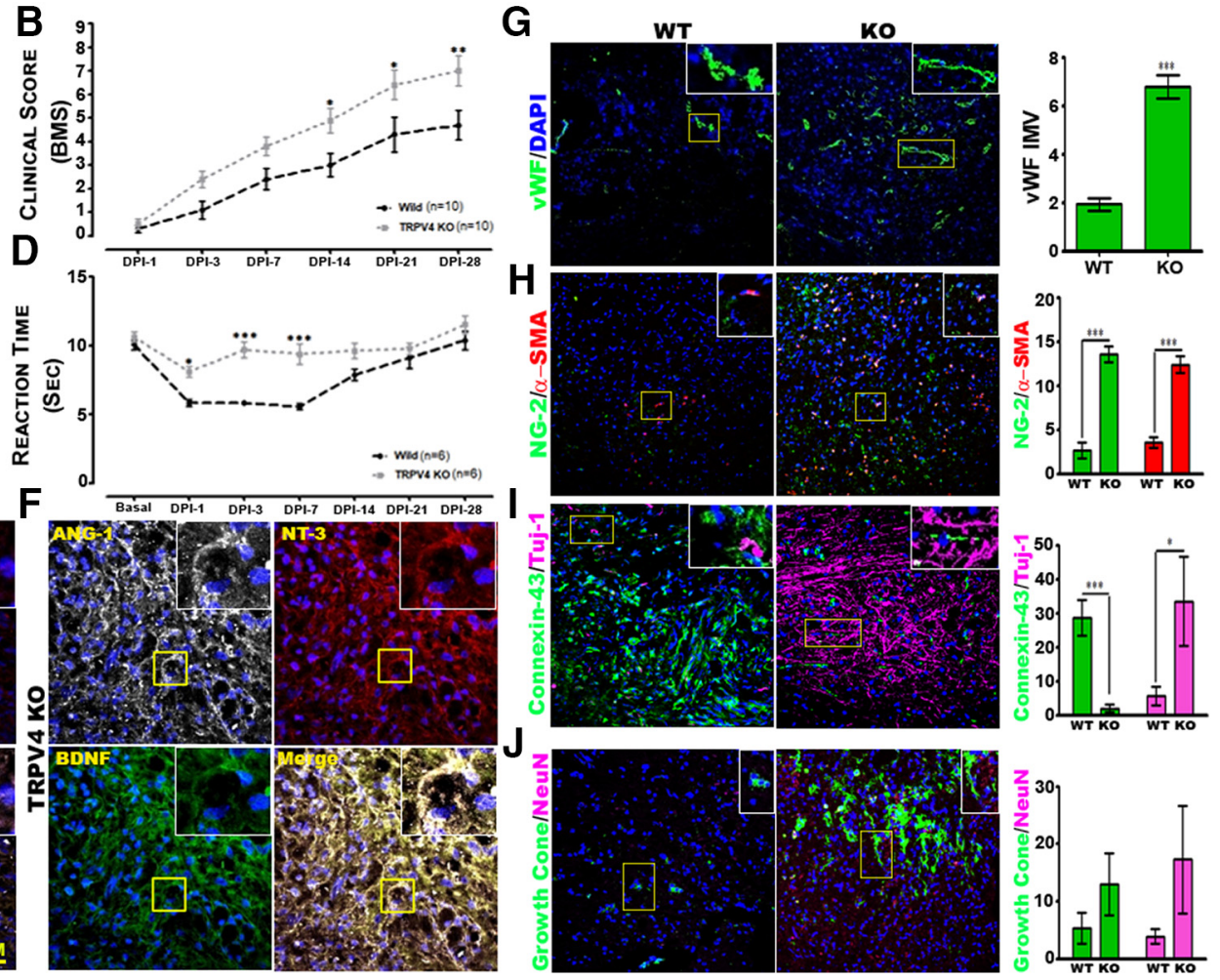

Figure 6. TRPV4 KO mice display reduced hyperalgesia, improved functional recovery, enhanced neuroprotection, and endothelial preservation after SCl. $A$, Representative images of H\&E staining at DPI-28 after SCI. B, Functional recovery was assessed in open-field testing by using the 9 -point BMS locomotor test at 1,3,7, 14, 21, and $28 \mathrm{~d}$ after $\mathrm{SCI}$ ( $n=10$ /group). $\boldsymbol{C}$, Nociception was evaluated using hotplate test. $\boldsymbol{D}$, SCl-induced hypersensitivity (decrease in reaction latency time) was assessed at pre-SCI (basal), 1,3,7, 14, 21, and $28 \mathrm{~d}$ after SCI ( $n=6 / \mathrm{group}$ ). Samples from WT (injury) or TRPV4 KO (injury) were prepared at DPI-28 as described in Materials and Methods. Representative sections of angiopoietin-1 (ANG-1, white), NT-3 (red), and BDNF (green) in WT (E) and KO (F). Representative section of VWF (G; green), neural/glial antigen NG-2 (H; green), $\alpha$-SMA ( $\boldsymbol{H}$; red), Connexin-43 (I; green), Tuj-1 (I; magenta); growth cone (green; $\boldsymbol{J})$, and NeuN (magenta, $\boldsymbol{J})$. Bar charts represent the IMV (fluorescence) for corresponding protein as per randomly selected field area at the injury epicenter ( 3 fields $/$ slide, $n=3 /$ group). Data are mean \pm SEM. ${ }^{*} p<0.05$, ${ }^{* *} p<0.01,{ }^{* * *} p<0.001$ vs WT-injury group.

stabilizing and supporting the spinal column using Allis clamps at T8 and T12 spinous processes. Ideally, the spinal cord should be parallel to the impounder during compression to avoid inconsistent parenchymal injury. Second, the compression with this method is only applied to dorsally to the spinal cord.

We also found that the expression of TRPV4 at the injury epicenter, but not $\left[\mathrm{Ca}^{2+}\right]_{\mathrm{i}}$, progressively increases with the severity of the injury. TRPV4 does not have an apparent $\mathrm{Ca}^{2+}$-binding site, such as an EF-hand, suggesting that $\mathrm{Ca}^{2+}$ does not bind directly to the channel. Cells expressing TRPV4 often display spontaneous channel activity, resulting in an elevated basal $\left[\mathrm{Ca}^{2+}\right]_{\mathrm{i}}$ (Plant and Strotmann, 2006), but there are also reports showing no changes in $\left[\mathrm{Ca}^{2+}\right]_{\mathrm{i}}$ in cells expressing TRPV4 (Strotmann et al., 2000). Nonetheless, in the present study, $\left[\mathrm{Ca}^{2+}\right]_{i}$ was increased after injury, regardless of the severity. Thus, our findings suggest that TRPV4 expression might be useful for predicting the severity of the CNS injury. We also observed progressive damage to the vascular endothelium and neurons (via RECA and NF immunoreactivity, respectively). Interestingly, RECA immunoreactivity was low at DPI- 1 when the expression of TRPV4 was high and matched the initial progressive damage to the endothelium, whereas axons showed progressive damage after SCI. These observations suggest that TRPV4 is increased and might promote the EC detachment following SCI.

Previous reports suggest that the expression of the TJ proteins occludin and $\mathrm{ZO}-1$ is downregulated after moderate compression injury (Kumar et al., 2018c), suggesting a disruption of the BSCB. In the present study, the expression of occludin decreased while that of inflammatory cytokines (IL-6 and others) increased, suggesting the direct involvement of TRPV4 in BSCB disruption and inflammation. The upregulation of TRPV4 after SCI was also associated with a decrease in Pacsin-3, a synaptic vesicular membrane trafficking protein that inhibits TRPV4 basal expression (D'hoedt et al., 2008), suggesting that the upregulation of TRPV4 has functional relevance. TRPV4 is expressed by vascular ECs in rodents (Watanabe et al., 2002; Zhang et al., 2009) and humans (Sullivan et al., 2012) and has also been identified in vascular smooth muscle cells (Senadheera et al., 2013) and in the astrocytic endfoot processes that wrap around blood vessels in the CNS (Benfenati et al., 2011).TRPV4 activation within the astrocytic endfeet contributes to neurovascular coupling via $\mathrm{Ca}^{2+}$ entry (Dunn et al., 2011).

Adhesion, tight, and gap junctions connect the ECs lining the vessel walls (Cerutti and Ridley, 2017). In the current study, pharmacological activation of TRPV4 decreased the expression of TJ markers (ZO-1, ZO-2, and claudin-1) and remodel adhesion junctions (via afadin and endothelial actin-binding protein CD2associated protein). In vivo application of a TRPV4 agonist led to EC damage and basal lamina deposition, which could diminish angiogenesis and promote cystic cavity formation, and enhanced EC damage after SCI. After SCI in rodents and humans, scarring occurs at the lesion site, comprising glial cells and laminin and fibronectin (Ruschel et al., 2015), which impedes axonal regeneration (Silver and Miller, 2004; Leal-Filho, 2011). However, the glial scars in animals receiving injections of the TRPV4 agonist were predominantly composed of microglia, which supports the 
notion that ion channels are also involved in regulating microglial functions (Färber and Kettenmann, 2005).

The activation of microglia after CNS injury is linked with neuroinflammation and impairments of the BBB/BSCB. TRPV4 activation also stimulates neuropeptide release from afferent nerves and induces neurogenic inflammation (Vergnolle et al., 2010). Whereas TRPV4 is activated by changes in osmolarity, which leads to increased IL- $1 \beta$ and IL- 6 in intervertebral discs and is suggestive of increased release of proinflammatory cytokines (Walter et al., 2016), we found that inhibition of TRPV4 (via $\mathrm{RN}-1734$ ) attenuated inflammation, reduced free $\left[\mathrm{Ca}^{2+}\right]_{\mathrm{i}}$ levels, and preserved the BSCB.

The functional properties of $\mathrm{TJ}$ components and the selective leakiness of the CNS TJs are well studied (Bazzoni and Dejana, 2004; Abbott et al., 2010). Damage to these proteins leads to BSCB instability and increased permeability, which promotes inflammatory infiltration in the CNS, the major determinant of secondary injury (Noble and Wrathall, 1989). The temporal and spatial increase of secondary damage after SCI has been attributed to the augmented expression of sulfonylurea receptor 1-regulated $\mathrm{NC}_{\text {Ca-ATP }}$ channels, such as Trpm4, by ECs (Gerzanich et al., 2009). In the present study, we found that ECs in animals with TRPV4 deficiency were protected from damage after SCI, suggesting that the activation of TRPV4 after injury might directly affect EC survival. A possible explanation is that TRPV4-mediated entry of $\mathrm{Ca}^{2+}$ into ECs regulates the production of nitric oxide and responses to inflammatory signals by changing the barrier properties (Tiruppathi et al., 2002). For example, knockdown of TRPV4 in adipocytes is inhibitory for an array of cytokines and chemokines in adipose tissues, suggesting that TRPV4 positively controls proinflammatory genes (Ye et al., 2012). Consistent with this, we found that TRPV4 KO mice had reduced inflammation and synthesis of chemokines and cytokines after SCI as well as enhanced EC integrity, reduced permeability, and reduced apoptosis. After SCI, the expression of ANG-1 was reduced. ANG-1 lowers vascular leakage/inflammation and expedites angiogenesis (Lee et al., 2009), by strengthening related endothelial molecules and regulating interendothelial adhesion. We found that the reduction in ANG-1 was attenuated in TRPV4 KO mice. Additionally, TRPV4 KO mice maintained the levels of several neurotrophins (BDNF and NT-3), which are linked with EC survival (Donovan et al., 2000), as well as levels of vWF, NG-2, and SMA. Notably, the detachment of ECs, which persists throughout the acute injury phase (Koyanagi et al., 1993), is an indirect contributor to neuronal and glial cell death (Casella et al., 2002).

Inflammation is well established in the pathology of SCI, and contributes to fibrosis scarring in part via TGF- $\beta$ signaling. The increase in TGF- $\beta / \mathrm{CD}-68$ expression after SCI was attenuated in TRPV4 KO mice. We also observed an SCI-induced increase in astrocytes, microglia, extracellular matrix proteins, and gap junctions. The persistence of these glial cells indicates a proinflammatory environment, linked with increased neurotoxicity and impaired wound healing. However, these increases were attenuated in TRPV4 KO mice, suggesting that the increase in TRPV4 observed in WT animals enhanced the scarring process. Indeed, SCI-induced endothelial damage was augmented, and glial scar formation was higher in animals injected with the TRPV4 agonist. Scarring leads to the formation of a sharp lesion border, which impairs neuronal regeneration (Bundesen et al., 2003), by forming a physical barrier preventing regenerating axons from extending across the injury site. A reduction of one or many specific cellular components of the scar can influence the scarring
(Meletis et al., 2008; Barnabé-Heider et al., 2010; Göritz et al., 2011; Zhu et al., 2015). Although TRPV4 also mediates neurotrophic factor-induced neuritogenesis in developing peripheral nerves (Jang et al., 2012), activation of this channel in the CNS via intracerebroventricular injection of the agonist induces neuronal apoptosis (Jie et al., 2015, 2016). Accordingly, we observed reduced immunoreactivity for NF, a cytoskeleton protein prominently expressed in larger axons, in animals injected with GSK, suggesting that TRPV4 activation affects large axons after SCI.

Finally, the sparing or regeneration of the vasculature and endothelial functions after injury correlates with improved functional outcomes (Kaneko et al., 2006). The above-described reduction in glial scarring and inflammation and enhanced expression of neuronal markers in KO mice suggest that TRPV4 contributes to the pathology of, and impaired recovery from, SCI. Accordingly, we observed reduced hyperalgesia toward heat and faster locomotor recovery in TRPV4 KO mice after SCI. The observed functional recovery might be attributed to reduced reactive gliosis. However, TRPV4 deficiency does not affect escape latency in response to heat in the absence of hyperalgesia (Liedtke and Friedman, 2003; Suzuki et al., 2003; Todaka et al., 2004), although an increase in tail withdrawal latency to moderately hot temperatures was reported (Lee et al., 2005). Other studies suggest that the channel contributes to the sensation of noxious mechanical stimuli (Liedtke and Friedman, 2003; Suzuki et al., 2003). Together, these data suggest that TRPV4 contributes to nociception only in the setting of inflammation or nerve injury (Alessandri-Haber et al., 2008).

In conclusion, TRPV4 expression is rapidly induced following SCI and in accordance with the severity of the injury. Its expression is linked to endothelial damage, inflammation, and apoptosis, thereby increasing secondary injury. Importantly, inhibition/ knockdown of TRPV4 prevented these effects. Thus, the manipulation of TRPV4 signaling might lead to new therapeutic strategies or combinatorial therapies to protect ECs and enhance repair after SCI.

\section{References}

Abbott NJ, Patabendige AA, Dolman DE, Yusof SR, Begley DJ (2010) Structure and function of the blood-brain barrier. Neurobiol Dis 37:13-25.

Alessandri-Haber N, Dina OA, Yeh JJ, Parada CA, Reichling DB, Levine JD (2004) Transient receptor potential vanilloid 4 is essential in chemotherapy-induced neuropathic pain in the rat. J Neurosci 24:4444-4452.

Alessandri-Haber N, Dina OA, Joseph EK, Reichling D, Levine JD (2006) A transient receptor potential vanilloid 4-dependent mechanism of hyperalgesia is engaged by concerted action of inflammatory mediators. J Neurosci 26:3864-3874.

Alessandri-Haber N, Dina OA, Joseph EK, Reichling DB, Levine JD (2008) Interaction of transient receptor potential vanilloid 4, integrin, and SRC tyrosine kinase in mechanical hyperalgesia. J Neurosci 28:1046-1057.

Barnabé-Heider F, Göritz C, Sabelström H, Takebayashi H, Pfrieger FW, Meletis K, Frisén J (2010) Origin of new glial cells in intact and injured adult spinal cord. Cell Stem Cell 7:470-482.

Basso DM, Fisher LC, Anderson AJ, Jakeman LB, McTigue DM, Popovich PG (2006) Basso mouse scale for locomotion detects differences in recovery after spinal cord injury in five common mouse strains. J Neurotrauma 23:635-659.

Bazzoni G, Dejana E (2004) Endothelial cell-to-cell junctions: molecular organization and role in vascular homeostasis. Physiol Rev 84:869-901.

Benfenati V, Caprini M, Dovizio M, Mylonakou MN, Ferroni S, Ottersen OP, Amiry-Moghaddam M (2011) An aquaporin-4/transient receptor potential vanilloid 4 (AQP4/TRPV4) complex is essential for cell-volume control in astrocytes. Proc Natl Acad Sci U S A 108:2563-2568.

Benton RL, Maddie MA, Worth CA, Mahoney ET, Hagg T, Whittermore SR (2008) Transcriptomic screening of microvascular endothelial cells im- 
plicates novel molecular regulators of vascular dysfunction after spinal cord injury. J Cereb Blood Flow Metab 28:1771-1785.

Bundesen LQ, Scheel TA, Bregman BS, Kromer LF (2003) Ephrin-B2 and EphB2 regulation of astrocyte-meningeal fibroblast interactions in response to spinal cord lesions in adult rats. J Neurosci 23:7789-7800.

Casella GT, Marcillo A, Bunge MB, Wood PM (2002) New vascular tissue rapidly replaces neural parenchyma and vessels destroyed by a contusion injury to the rat spinal cord. Exp Neurol 173:63-76.

Casella GT, Bunge MB, Wood PM (2006) Endothelial cell loss is not a major cause of neuronal and glial cell death following contusion injury of the spinal cord. Exp Neurol 202:8-20.

Cerutti C, Ridley AJ (2017) Endothelial cell-cell adhesion and signaling. Exp Cell Res 358:31-38.

D'hoedt D, Owsianik G, Prenen J, Cuajungco MP, Grimm C, Heller S, Voets T, Nilius B (2008) Stimulus-specific modulation of the cation channel TRPV4 by PACSIN 3. J Biol Chem 283:6272-6280.

Donovan MJ, Lin MI, Wiegn P, Ringstedt T, Kraemer R, Hahn R, Wang S, Ibañez CF, Rafii S, Hempstead BL (2000) Brain derived neurotrophic factor is an endothelial cell survival factor required for intramyocardial vessel stabilization. Development 127:4531-4540.

Dunn KM, Bonev AD, Nelson MT (2011) Functional evidence of TRPV4mediated $\mathrm{Ca}^{2+}$ signals in cortical astrocytes. FASEB J 25:1023-1024.

Färber K, Kettenmann H (2005) Physiology of microglial cells. Brain Res Brain Res Rev 48:133-143.

Fassbender JM, Whittemore SR, Hagg T (2011) Targeting microvasculature for neuroprotection after SCI. Neurotherapeutics 8:240-251.

Gerzanich V, Woo SK, Vennekens R, Tsymbalyuk O, Ivanova S, Ivanov A, Geng Z, Chen Z, Nilius B, Flockerzi V, Freichel M, Simard JM (2009) De novo expression of Trpm4 initiates secondary hemorrhage in spinal cord injury. Nat Med 15:185-191.

Göritz C, Dias DO, Tomilin N, Barbacid M, Shupliakov O, Frisén J (2011) A pericyte origin of spinal cord scar tissue. Science 333:238-242.

Grant AD, Cottrell GS, Amadesi S, Trevisani M, Nicoletti P, Materazzi S, Altier C, Cenac N, Zamponi GW, Bautista-Cruz F, Lopez CB, Joseph EK, Levine JD, Liedtke W, Vanner S, Vergnolle N, Geppetti P, Bunnett NW (2007) Protease-activated receptor 2 sensitizes the transient receptor potential vanilloid 4 ion channel to cause mechanical hyperalgesia in mice. J Physiol 578:715-733.

Guo S, Kim WJ, Lok J, Lee SR, Besancon E, Luo BH, Stins MF, Wang X, Dedhar S, Lo EH (2008) Neuroprotection via matrix-trophic coupling between cerebral endothelial cells and neurons. Proc Natl Acad Sci U S A 105:7582-7587.

Jang Y, Jung J, Kim H, Oh J, Jeon JH, Jung S, Kim KT, Cho H, Yang DJ, Kim SM, Kim IB, Song MR, Oh U (2012) Axonal neuropathy-associated TRPV4 regulates neurotrophic factor-derived axonal growth. J Biol Chem 287:6014-6024.

Jie P, Hong Z, Tian Y, Li Y, Lin L, Zhou L, Du Y, Chen L, Chen L (2015) Activation of transient receptor potential vanilloid 4 induces apoptosis in hippocampus through downregulating PI3K/Akt and upregulating p38 MAPK signaling pathways. Cell Death Dis 6:e1775.

Jie P, Lu Z, Hong Z, Li L, Zhou L, Li Y, Zhou R, Zhou Y, Du Y, Chen L, Chen L (2016) Activation of transient receptor potential vanilloid 4 is involved in neuronal injury in middle cerebral artery occlusion in mice. Mol Neurobiol 53:8-17.

Kaneko S, Iwanami A, Nakamura M, Kishino A, Kikuchi K, Shibata S, Okano HJ, Ikegami T, Moriya A, Konishi O, Nakayama C, Kumagai K, Kimura T, Sato Y, Goshima Y, Taniguchi M, Ito M, He Z, Toyama Y, Okano H (2006) A selective Sema3A inhibitor enhances regenerative responses and functional recovery of the injured spinal cord. Nat Med 12:13801389.

Kim HJ, Lim CS, Lee HW, Lee HS, Um YJ, Kumar H, Han I, Kim HM (2017) A ratiometric two-photon probe for $\mathrm{Ca}^{2+}$ in live tissues and its application to spinal cord injury model. Biomaterials 141:251-259.

Koyanagi I, Tator CH, Lea PJ (1993) Three-dimensional analysis of the vascular system in the rat spinal cord with scanning electron microscopy of vascular corrosion casts: 2 . Acute spinal cord injury. Neurosurgery 33 : 285-292.

Kumar H, Lee SH, Kim KT, Zeng X, Han I (2018a) TRPV4: a sensor for homeostasis and pathological events in the CNS. Mol Neurobiol 55: 8695-8708.

Kumar H, Jo MJ, Choi H, Muttigi MS, Shon S, Kim BJ, Lee SH, Han IB (2018b) Matrix metalloproteinase-8 inhibition prevents disruption of blood-spinal cord barrier and attenuates inflammation in rat model of spinal cord injury. Mol Neurobiol 55:2577-2590.

Kumar H, Choi H, Jo MJ, Joshi HP, Muttigi M, Bonanomi D, Kim SB, Ban E, Kim A, Lee SH, Kim KT, Sohn S, Zeng X, Han I (2018c) Neutrophil elastase inhibition effectively rescued angiopoietin-1 decrease and inhibits glial scar after spinal cord injury. Acta Neuropathol Commun 6:73.

Leal-Filho MB (2011) Spinal cord injury: from inflammation to glial scar. Surg Neurol Int 2:112.

Lee HS, Han J, Bai HJ, Kim KW (2009) Brain angiogenesis in developmental and pathological processes: regulation, molecular and cellular communication at the neurovascular interface. FEBS J 276:4622-4635.

Lee H, Iida T, Mizuno A, Suzuki M, Caterina MJ (2005) Altered thermal selection behavior in mice lacking transient receptor potential vanilloid 4 . J Neurosci 25:1304-1310.

Liedtke W, Friedman JM (2003) Abnormal osmotic regulation in trpv4 $4^{-1-}$ mice. Proc Natl Acad Sci U S A 100:13698-13703.

Liedtke W, Choe Y, Martí-Renom MA, Bell AM, Denis CS, Sali A, Hudspeth AJ, Friedman JM, Heller S (2000) Vanilloid receptor-related osmotically activated channel (VR-OAC), a candidate vertebrate osmoreceptor. Cell 103:525-535.

Ling X, Liu D (2007) Temporal and spatial profiles of cell loss after spinal cord injury: reduction by a metalloporphyrin. J Neurosci Res 85:21752185.

Liu XZ, Xu XM, Hu R, Du C, Zhang SX, McDonald JW, Dong HX, Wu YJ, Fan GS, Jacquin MF, Hsu CY, Choi DW (1997) Neuronal and glial apoptosis after traumatic spinal cord injury. J Neurosci 17:5395-5406.

Meletis K, Barnabé-Heider F, Carlén M, Evergren E, Tomilin N, Shupliakov O, Frisén J (2008) Spinal cord injury reveals multilineage differentiation of ependymal cells. PLoS Biol 6:e182.

Montell C, Birnbaumer L, Flockerzi V (2002) The TRP channels, a remarkably functional family. Cell 108:595-598.

Narita K, Sasamoto S, Koizumi S, Okazaki S, Nakamura H, Inoue T, Takeda S (2015) TRPV4 regulates the integrity of the blood-cerebrospinal fluid barrier and modulates transepithelial protein transport. FASEB J 29: 2247-2259.

National Research Council (2011) Guide for the care and use of laboratory animals. Washington, DC: National Research Council.

Nilius B, Droogmans G (2001) Ion channels and their functional role in vascular endothelium. Physiol Rev 81:1415-1459.

Nilius B, Prenen J, Wissenbach U, Bödding M, Droogmans G (2001) Differential activation of the volume-sensitive cation channel TRP12 (OTRPC4) and volume-regulated anion currents in HEK-293 cells. Pflugers Archiv 443:227-233.

Noble LJ, Wrathall JR (1989) Distribution and time course of protein extravasation in the rat spinal cord after contusive injury. Brain Res 482:5766.

Plant TD, Strotmann R (2006) TRPV4: a multifunctional nonselective cation channel with complex regulation. In: TRP ion channel function in sensory transduction and cellular signaling cascades, pp 139-154. Boca Raton, FL: CRC.

Ramsey IS, Delling M, Clapham DE (2006) An introduction to TRP channels. Annu Rev Physiol 68:619-647.

Ropper AE, Zeng X, Anderson JE, Yu D, Han I, Haragopal H, Teng YD (2015) An efficient device to experimentally model compression injury of mammalian spinal cord. Exp Neurol 271:515-523.

Ruschel J, Hellal F, Flynn KC, Dupraz S, Elliott DA, Tedeschi A, Bates M, Sliwinski C, Brook G, Dobrindt K, Peitz M, Brüstle O, Norenberg MD, Blesch A, Weidner N, Bunge MB, Bixby JL, Bradke F (2015) Axonal regeneration. systemic administration of epothilone B promotes axon regeneration after spinal cord injury. Science 348:347-352.

Ryskamp DA, Jo AO, Frye AM, Vazquez-Chona F, MacAulay N, Thoreson WB, Krizaj D (2014) Swelling and eicosanoid metabolites differentially gate TRPV4 channels in retinal neurons and glia. J Neurosci 34: $15689-15700$.

Senadheera S, Bertrand PP, Grayson TH, Leader L, Murphy TV, Sandow SL (2013) Pregnancy-induced remodelling and enhanced endotheliumderived hyperpolarization-type vasodilator activity in rat uterine radial artery: transient receptor potential vanilloid type 4 channels, caveolae and myoendothelial gap junctions. J Anat 223:677-686.

Sharif-Alhoseini M, Khormali M, Rezaei M, Safdarian M, Hajighadery A, Khalatbari MM, Meknatkhah S, Rezvan M, Chalangari M, Derakhshan P, 
Rahimi-Movaghar V (2017) Animal models of spinal cord injury: a systematic review. Spinal Cord 55:714-721.

Shi M, Du F, Liu Y, Li L, Cai J, Zhang GF, Xu XF, Lin T, Cheng HR, Liu XD, Xiong LZ, Zhao G (2013) Glial cell-expressed mechanosensitive channel TRPV4 mediates infrasound-induced neuronal impairment. Acta Neuropathol 126:725-739.

Shibasaki K, Ikenaka K, Tamalu F, Tominaga M, Ishizaki Y (2014) A novel subtype of astrocytes expressing TRPV4 (transient receptor potential vanilloid 4) regulates neuronal excitability via release of gliotransmitters. J Biol Chem 289:14470-14480.

Silver J, Miller JH (2004) Regeneration beyond the glial scar. Nat Rev Neurosci 5:146-156.

Strotmann R, Harteneck C, Nunnenmacher K, Schultz G, Plant TD (2000) OTRPC4, a nonselective cation channel that confers sensitivity to extracellular osmolarity. Nat Cell Biol 2:695-702.

Strotmann R, Schultz G, Plant TD (2003) $\mathrm{Ca}^{2+}$-dependent potentiation of the nonselective cation channel TRPV4 is mediated by a C-terminal calmodulin binding site. J Biol Chem 278:26541-26549.

Sullivan MN, Francis M, Pitts NL, Taylor MS, Earley S (2012) Optical recording reveals novel properties of GSK1016790A-induced vanilloid transient receptor potential channel TRPV4 activity in primary human endothelial cells. Mol Pharmacol 82:464-472.

Suzuki M, Mizuno A, Kodaira K, Imai M (2003) Impaired pressure sensation in mice lacking TRPV4. J Biol Chem 278:22664-22668.

Tiruppathi C, Freichel M, Vogel SM, Paria BC, Mehta D, Flockerzi V, Malik $A B$ (2002) Impairment of store-operated $\mathrm{Ca}^{2+}$ entry in TRPC4 ${ }^{-1-}$ mice interferes with increase in lung microvascular permeability. Circ Res 91:70-76.

Todaka H, Taniguchi J, Satoh J, Mizuno A, Suzuki M (2004) Warm temperature-sensitive transient receptor potential vanilloid 4 (TRPV4) plays an essential role in thermal hyperalgesia. J Biol Chem 279:35133-35138.

Vergnolle N, Cenac N, Altier C, Cellars L, Chapman K, Zamponi GW, Materazzi S, Nassini R, Liedtke W, Cattaruzza F, Grady EF, Geppetti P, Bunnett NW (2010) A role for transient receptor potential vanilloid 4 in tonicity-induced neurogenic inflammation. Br J Pharmacol 159:11611173.

Walter BA, Purmessur D, Moon A, Occhiogrosso J, Laudier DM, Hecht AC, Iatridis JC (2016) Reduced tissue osmolarity increases TRPV4 expres- sion and pro-inflammatory cytokines in intervertebral disc cells. Eur Cell Mater 32:123-136.

Watanabe H, Vriens J, Suh SH, Benham CD, Droogmans G, Nilius B (2002) Heat-evoked activation of TRPV4 channels in a HEK293 cell expression system and in native mouse aorta endothelial cells. J Biol Chem 277: 47044-47051.

Whetstone WD, Hsu JY, Eisenberg M, Werb Z, Noble-Haeusslein LJ (2003) Blood-spinal cord barrier after spinal cord injury: relation to revascularization and wound healing. J Neurosci Res 74:227-239.

Willette RN, Bao W, Nerurkar S, Yue TL, Doe CP, Stankus G, Turner GH, Ju H, Thomas H, Fishman CE, Sulpizio A, Behm DJ, Hoffman S, Lin Z, Lozinskaya I, Casillas LN, Lin M, Trout RE, Votta BJ, Thorneloe K, et al. (2008) Systemic activation of the transient receptor potential vanilloid subtype 4 channel causes endothelial failure and circulatory collapse: part 2. J Pharmacol Exp Ther 326:443-452.

Ye L, Kleiner S, Wu J, Sah R, Gupta RK, Banks AS, Cohen P, Khandekar MJ, Boström P, Mepani RJ, Laznik D, Kamenecka TM, Song X, Liedtke W, Mootha VK, Puigserver P, Griffin PR, Clapham DE, Spiegelman BM (2012) TRPV4 is a regulator of adipose oxidative metabolism, inflammation, and energy homeostasis. Cell 151:96-110.

Yu D, Thakor DK, Han I, Ropper AE, Haragopal H, Sidman RL, Zafonte R, Schachter SC, Teng YD (2013) Alleviation of chronic pain following rat spinal cord compression injury with multimodal actions of huperzine A. Proc Natl Acad Sci U S A 110:E746-E755.

Zhang DX, Mendoza SA, Bubolz AH, Mizuno A, Ge ZD, Li R, Warltier DC, Suzuki M, Gutterman DD (2009) Transient receptor potential vanilloid type 4-deficient mice exhibit impaired endothelium-dependent relaxation induced by acetylcholine in vitro and in vivo. Hypertension 53: 532-538.

Zhao P, Lieu T, Barlow N, Metcalf M, Veldhuis NA, Jensen DD, Kocan M, Sostegni S, Haerteis S, Baraznenok V, Henderson I, Lindström E, Guerrero-Alba R, Valdez-Morales EE, Liedtke W, McIntyre P, Vanner SJ, Korbmacher C, Bunnett NW (2014) Cathepsin S causes inflammatory pain via biased agonism of PAR2 and TRPV4. J Biol Chem 289:2721527234.

Zhu Y, Soderblom C, Trojanowsky M, Lee DH, Lee JK (2015) Fibronectin matrix assembly after spinal cord injury. J Neurotrauma 32:1158-1167. 